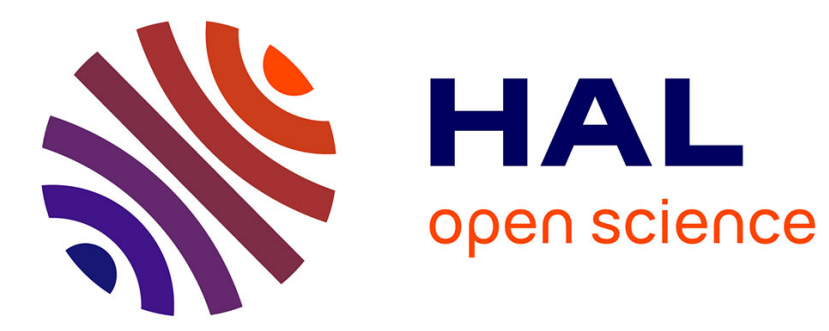

\title{
Near-surface geophysical methods for investigating the Buyukcekmece landslide in Istanbul, Turkey
}

Esref Yacinlkaya, Hakan Alp, Oguz Ozel, Ethem Gorgun, Salvatore Martino, Luca Lenti, Céline Bourdeau Lombardi, Pascal Bigarre, Stellia Coccia

\section{- To cite this version:}

Esref Yacinlkaya, Hakan Alp, Oguz Ozel, Ethem Gorgun, Salvatore Martino, et al.. Near-surface geophysical methods for investigating the Buyukcekmece landslide in Istanbul, Turkey. Journal of Applied Geophysics, 2016, 134, pp. 23-35. 10.1016/j.jappgeo.2016.08.012 . hal-01724162

\author{
HAL Id: hal-01724162 \\ https://hal.science/hal-01724162
}

Submitted on 28 Aug 2018

HAL is a multi-disciplinary open access archive for the deposit and dissemination of scientific research documents, whether they are published or not. The documents may come from teaching and research institutions in France or abroad, or from public or private research centers.
L'archive ouverte pluridisciplinaire HAL, est destinée au dépôt et à la diffusion de documents scientifiques de niveau recherche, publiés ou non, émanant des établissements d'enseignement et de recherche français ou étrangers, des laboratoires publics ou privés. 


\title{
Near-surface geophysical methods for investigating of Buyukcekmece
}

\section{landslide in Istanbul, Turkey}

\author{
Esref Yalcinkaya a, ${ }^{a,}$, Hakan Alp ${ }^{a}$, Oguz Ozel ${ }^{\mathrm{a}}$, Ethem Gorgun ${ }^{\mathrm{a}}$, Salvatore Martino ${ }^{\mathrm{b}}$, Luca Lenti ${ }^{\mathrm{c}}$, Celine \\ Bourdeau $^{\mathrm{c}}$, Pascal Bigarre ${ }^{\mathrm{d}}$, Stella Coccia $^{\mathrm{d}}$
}

\author{
${ }^{a}$ Istanbul University, Engineering Faculty, Geophysical Engineering, 34320 Avcilar, Istanbul, TURKEY, \\ eyalcin@istanbul.edu.tr \\ ${ }^{\mathrm{b}}$ Department of Earth Sciences and Research Center for the Geological Risks (CERI) of the University of Rome \\ "Sapienza" \\ ${ }^{c}$ French Institute of Sciences and Technology for Transport, Development and Network (IFSTTAR-Paris) \\ ${ }^{\mathrm{d}}$ INERIS Ecole des Mines des Nancy Campus ARTEM CS 14234 F-54042 Nancy Cedex France \\ *Corresponding author
}

\section{Abstract}

In this study, near surface geophysical techniques are experienced to investigate physical characteristics of the Buyukcekmece landslide (Istanbul, Turkey). The Buyukcekmece landslide has a continuous activity with a low velocity, and is classified as a complex mechanism. It includes rototranslational parts, several secondary scarps, several landslide terraces, and evidences of two earth flows. It mainly develops in the clayey layers of the Danismen Formation. According to our findings, P-wave velocities ranging from $300 \mathrm{~m} / \mathrm{s}$ to $2400 \mathrm{~m} / \mathrm{s}$ do not provide a notable discrimination between sliding mass and stable soil. They show variations in blocks reflecting complex structure. We obtained S-wave velocity structure of the landslide up to $80 \mathrm{~m}$ by combining analysis of MASW and ReMi. It is clear that Swave velocities are lower on the landslide if compared those of the stable area. Being the same of the S-wave velocities for the entire area at depths higher than $60 \mathrm{~m}$ may point out the maximum thickness of the landslide mass. Resonance frequencies obtained from the $\mathrm{H} / \mathrm{V}$ analysis on the landslide area are generally higher than those on the stable area. The depths computed by using an empirical relation between the resonance frequency and the soil thickness point out the failure surfaces from 10 to $50 \mathrm{~m}$ moving downslope from the landslide crown area. The resistivity values within the landslide are generally lower than $30 \mathrm{ohm}-\mathrm{m}$, i.e. a typical value for remolded clayey debris. The geophysical results reflect an overview of the geological model, but the complexity of landslide makes difficult the mapping of the landslide structure in detail.

Keywords: Landslide, failure surface, geophysical techniques, Buyukcekmece, earthquake, Marmara 


\section{Introduction}

The Marmara region of Turkey is getting ready for the expected Istanbul or Marmara earthquake (Fig. 1). A number of studies performed after the devastating 1999 Izmit (M7.4) and Duzce (M7.2) earthquakes characterize the Marmara fault, which is the part of North Anatolian Fault (NAF) extending under the Marmara Sea, as a seismic gap with high potential for producing large earthquake $(M>7)$ (Parsons et al., 2000; Hubert-Ferrari et al., 2000; King et al., 2001; Barka et al., 2002; Parsons, 2004; Pondard et al., 2007). A last study made by Utkucu et al. (2009) describes the Marmara region, which has imminent seismic hazard. In the region, many studies have been performing related with not only understanding of seismic hazard but also mitigation of seismic risk. The project of MARSite (New directions in seismic hazard assessment through focused earth observation in the Marmara Supersite, http://marsite.eu) is one of such study financed by European Union-FP7. It consists of 11 work packages which has a wide study range from geodetic monitoring to early warning. The $6^{\text {th }}$ work package of MARSite project, which constitutes the base of this study, focuses on the earthquake-induced landslide hazard in the Marmara region.

Earthquake-triggered landslides have an increasing disastrous impact in seismic regions due to the fast growing urbanization and infrastructures. Just considering disasters from the last fifteen years, among which the 1999 Chi-Chi earthquake, the 2008 Wenchuan earthquake, and the 2011 Tohoku earthquake, these events generated tens of thousands of co-seismic landslides. Those resulted in amazing death toll and considerable damages, affecting the regional landscape including its hydrological main features. The last seven years' recordings demonstrated that more than $50 \%$ of the total losses due to landslides worldwide are attributed to co-seismic slope failures (Petley, 2010). Moreover, as reported by Bird and Bommer (2004), the greatest damage caused by earthquakes is often related to landslides.

Besides the high level of seismic risk, landslides in Turkey constitute the second source of life and economical losses induced by natural hazards. In fact, the 1999 Izmit earthquake (M7.4) caused numerous landslides on the north part of the Marmara Sea, especially along the western shores of Istanbul. In the Marmara Region, the earthquake-triggered landslides risk is steadily increasing due to the growing "urban pressure" over landslide prone areas. Especially the Avcilar-Beylikduzu Peninsula situated between Kucukcekmece and Buyukcekmece Lakes in the westward of Istanbul (Fig. 2) is an active landslide area when considering high seismic landslide risk because of extensively constructed and rapid increase in population. In the 
Marmara region where a disastrous earthquake is expected, the earthquake-triggered landslides, their characterization and monitoring and also early warning issue are key issues in terms of public safety and disaster prevention.

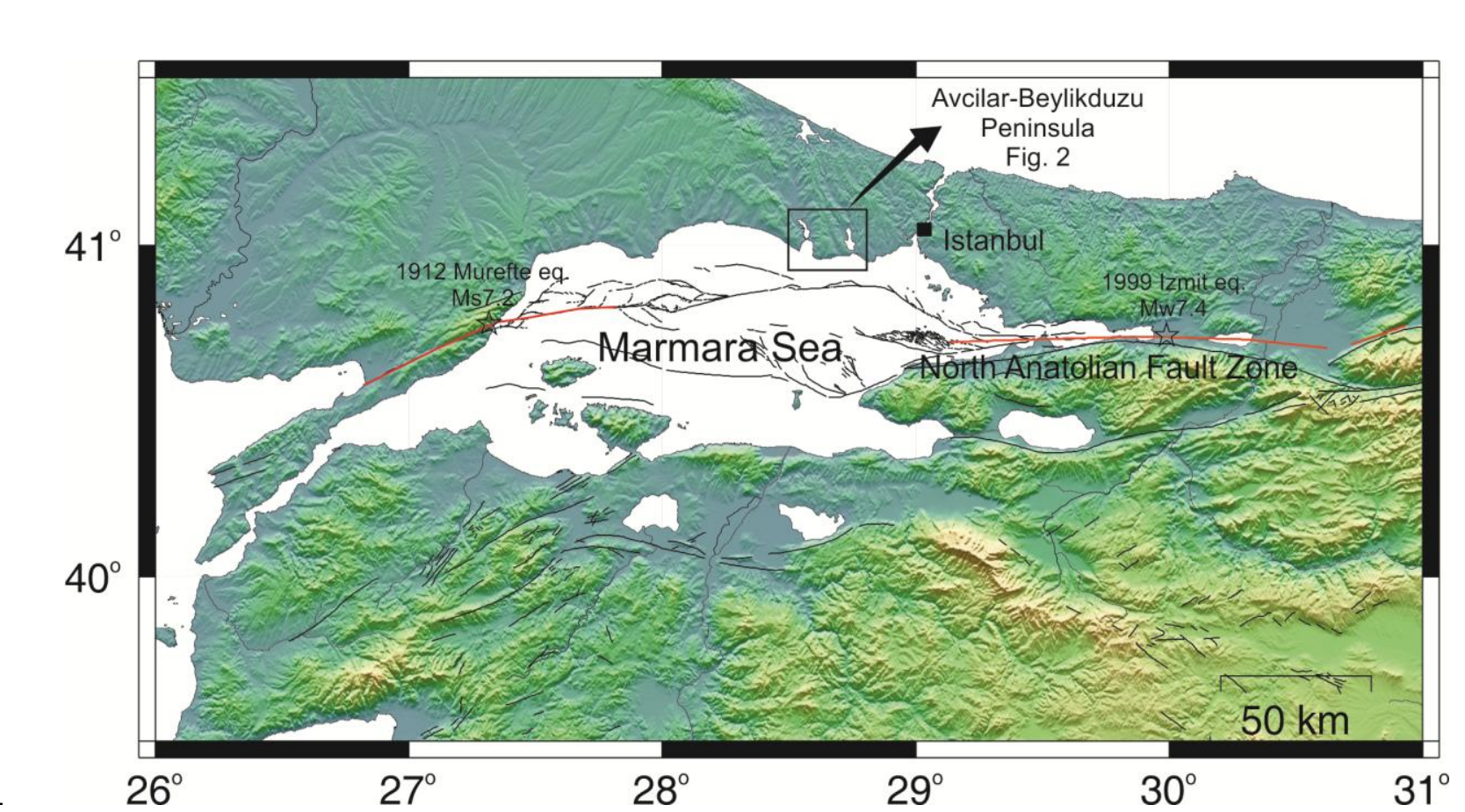

Figure 1. North Anatolian Fault Zone (NAF) extending in the Marmara Region of Turkey (black lines), and the surface ruptures of last two earthquakes occurred on the NAF (red lines).

In the last decade, near-surface geophysical techniques have been widely used for characterization of landslides (e.g. Meric et al., 2007; Jongmans et al., 2009). The applications based on that moving mass of landslide have different physical properties in terms of surrounding rock or stable soil due to exposed to deformations, fractures, water content, and porosity. There are two main targets of geophysical investigations: the first is the location of the vertical and lateral boundaries of the landslide, that is the failure surface, and the second is the mapping of the internal structure of the landslide (Jongmans and Grambois, 2007) . A boundary or contrast in properties of sub-surface layers can be readily available by geophysical methods. However, this boundary may not be always sufficiently strong to be explored by geophysical methods or the resolution of applied techniques may not adequate to locate the potential slip surface. According to McCann and Forster (1990), the success of any 
geophysical technique depends on four main controlling factors: the existence of a geophysical contrast differentiating the body to be mapped, the resolution and penetration of the method, the calibration of geophysical techniques by geological or geotechnical data and, finally, the signal to noise ratio. While the electrical and seismic methods were the most used geophysical methods in the past, the seismic noise and ground-penetrating radar measurements were added to those in the last years (Caris and Van Asch, 1991; Gallipoli et al., 2000; Schmutz et al., 2000; Lapenna et al., 2005; Meric et al., 2007). The advantage or disadvantage of a method to the others vary depending on the landslide specifications and data acquisition parameters. Using of integrated geophysical methods and inversion of geophysical data constrained by stratigraphic information allow to significantly increase reliability of geophysical models (Meric et al., 2007; Keay et al., 2009; Chianese et al., 2010; Panzera and Lombardo, 2013; Capizzi and Martorana, 2014). A broad review about the advantages and disadvantages of the geophysical techniques on the landslide characterization can be found in Hack (2000) and Jongmans and Grambois (2007). In general, low resistivity values and low seismic velocities characterize landslide body in terms of undisturbed soil. Resistivity values of landslide body in compact clays and marls decrease 10-30 $\Omega . m$ depending on weathering extent and water content, while the undisturbed soil is characterized by a resistivity over 60-75 $\Omega . m$ (Caris and Van Asch, 1991; Lapenna et al., 2005; Meric et al., 2007). Mostly strong P and S-wave velocity contrasts were found between the landslide body $\left(\mathrm{V}_{\mathrm{p}}<400 \mathrm{~m} / \mathrm{s}, \mathrm{V}_{\mathrm{s}}<300 \mathrm{~m} / \mathrm{s}\right)$ and the basement $\left(\mathrm{V}_{\mathrm{p}}>1500 \mathrm{~m} / \mathrm{s}, \mathrm{V}_{\mathrm{s}}>500 \mathrm{~m} / \mathrm{s}\right)($ Caris and $\mathrm{Van}$ Asch, 1991; Meric et al., 2007; Jongmans et al., 2009). On the other hand, the examples which these differentiations between landslide body and surrounding material cannot be monitored are also available (Jongmans et al., 2009).

This paper covers the analyses of near-surface geophysical measurements aiming to reveal the vertical and lateral boundaries of the Buyukcekmece landslide, which is chosen as pilot investigation site in the frame of $6^{\text {th }}$ work package of the Marsite Project. An additional target is the mapping of the internal structure of the landslide for the stability analyses under the seismic shaking. Geophysical results will be compared with the geological models constructed preliminary by geological and morphological observations. 


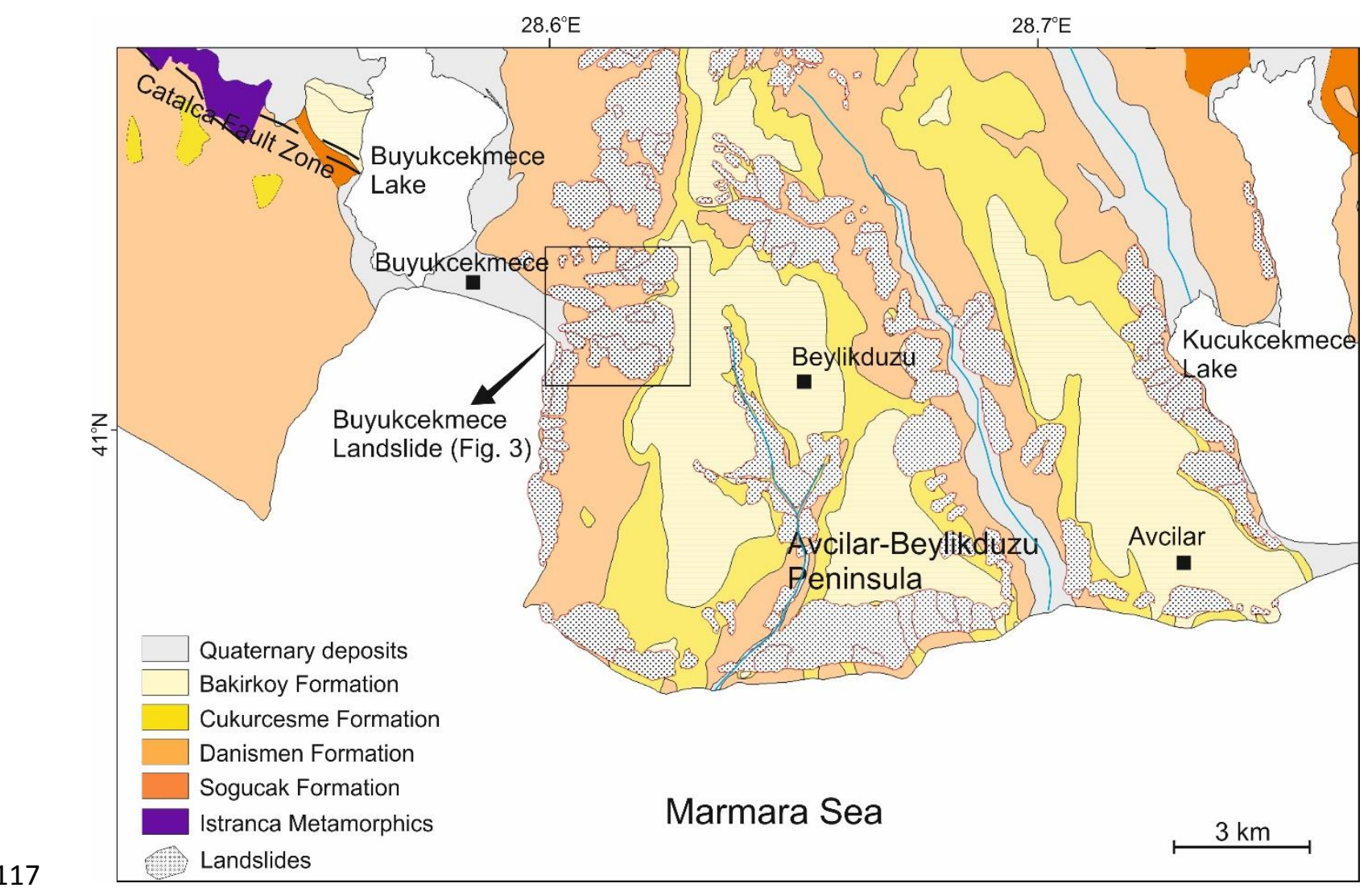

Figure 2. Landslide map and simplified geology of the Avcilar-Beylikduzu Peninsula (modified from Duman et al., 2004; Ozgul et al., 2005 and Ergintav et al., 2011).

\section{Buyukcekmece landslide}

The Buyukcekmece landslide takes place in the Avcilar-Beylikduzu peninsula in the western part of Istanbul metropolitan area (Fig. 2). The NAF passes through the distance of about 15 $\mathrm{km}$ from south of the study area. The study area is bordered by the Marmara Sea in the south. While the topography sharply increases from the sea coast to 50-100 m elevation in the south, it has a plateau character elevated gently toward to the north. This plateau is incised and dissected by river channels flowing to the Marmara Sea. Both river slopes and coastal slopes are active landslide areas. The materials attached loosely on steep slopes flow downward. Rainfall, topographic slope, human activity and seismic motions can be regarded as possible triggers for landslides in this area. While the youngest geological units take place on the top of the plateau, it is possible to see the older units on the bottom of river channels and the coastal slopes (Dalgic, 2004; Duman et al., 2006; Sen, 2007). The Avcilar-Beylikduzu peninsula is of particular interest for landslide susceptibility to earthquake triggering as: $i$ ) it 


\title{
Near-surface geophysical methods for investigating of Buyukcekmece
}

\section{landslide in Istanbul, Turkey}

\author{
Esref Yalcinkaya a, ${ }^{a,}$, Hakan Alp ${ }^{a}$, Oguz Ozel ${ }^{\mathrm{a}}$, Ethem Gorgun ${ }^{\mathrm{a}}$, Salvatore Martino ${ }^{\mathrm{b}}$, Luca Lenti ${ }^{\mathrm{c}}$, Celine \\ Bourdeau $^{\mathrm{c}}$, Pascal Bigarre ${ }^{\mathrm{d}}$, Stella Coccia $^{\mathrm{d}}$
}

\author{
${ }^{a}$ Istanbul University, Engineering Faculty, Geophysical Engineering, 34320 Avcilar, Istanbul, TURKEY, \\ eyalcin@istanbul.edu.tr \\ ${ }^{\mathrm{b}}$ Department of Earth Sciences and Research Center for the Geological Risks (CERI) of the University of Rome \\ "Sapienza" \\ ${ }^{c}$ French Institute of Sciences and Technology for Transport, Development and Network (IFSTTAR-Paris) \\ ${ }^{\mathrm{d}}$ INERIS Ecole des Mines des Nancy Campus ARTEM CS 14234 F-54042 Nancy Cedex France \\ *Corresponding author
}

\section{Abstract}

In this study, near surface geophysical techniques are experienced to investigate physical characteristics of the Buyukcekmece landslide (Istanbul, Turkey). The Buyukcekmece landslide has a continuous activity with a low velocity, and is classified as a complex mechanism. It includes rototranslational parts, several secondary scarps, several landslide terraces, and evidences of two earth flows. It mainly develops in the clayey layers of the Danismen Formation. According to our findings, P-wave velocities ranging from $300 \mathrm{~m} / \mathrm{s}$ to $2400 \mathrm{~m} / \mathrm{s}$ do not provide a notable discrimination between sliding mass and stable soil. They show variations in blocks reflecting complex structure. We obtained S-wave velocity structure of the landslide up to $80 \mathrm{~m}$ by combining analysis of MASW and ReMi. It is clear that Swave velocities are lower on the landslide if compared those of the stable area. Being the same of the S-wave velocities for the entire area at depths higher than $60 \mathrm{~m}$ may point out the maximum thickness of the landslide mass. Resonance frequencies obtained from the $\mathrm{H} / \mathrm{V}$ analysis on the landslide area are generally higher than those on the stable area. The depths computed by using an empirical relation between the resonance frequency and the soil thickness point out the failure surfaces from 10 to $50 \mathrm{~m}$ moving downslope from the landslide crown area. The resistivity values within the landslide are generally lower than $30 \mathrm{ohm}-\mathrm{m}$, i.e. a typical value for remolded clayey debris. The geophysical results reflect an overview of the geological model, but the complexity of landslide makes difficult the mapping of the landslide structure in detail.

Keywords: Landslide, failure surface, geophysical techniques, Buyukcekmece, earthquake, Marmara 
Formations outcrop in the main scarp of the landslide (Fig. 2). As it is resulted from field surveys, the deposits belonging to the Bakirkoy, Cukurcesme and Danismen Formations are involved the landslide mass. Nevertheless, due to the existence of several secondary scarps the original geological setting of the deposits is significantly modified as counterslope tilted landslide blocks can be surveyed in the landslide mass area (Fig. 3).

\section{+ Seismic measurements \\ Noise measurements \\ $\triangle$ Resistivity measurements Landslide boundary Landslide scarp Landslide terrace Earth flows}

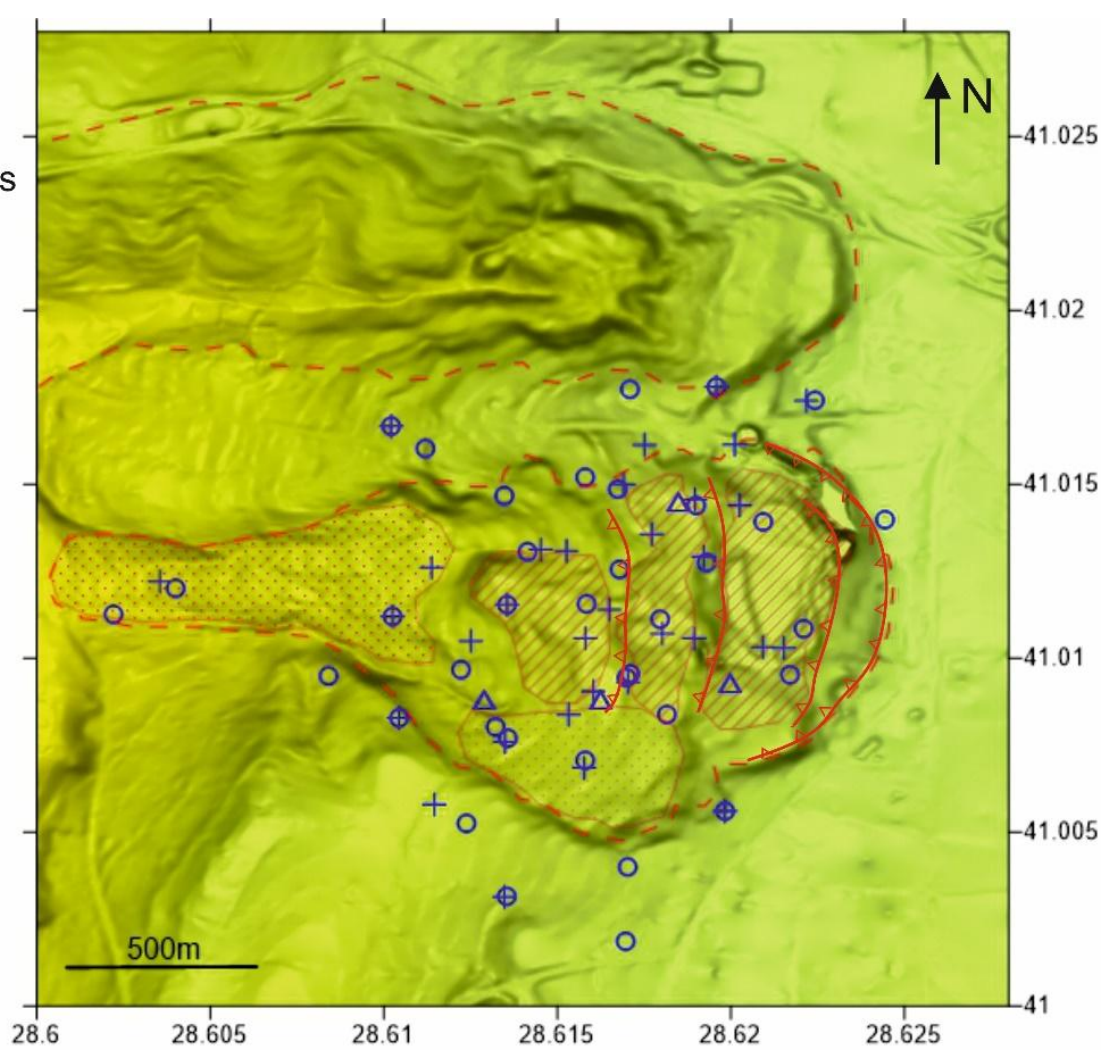

Figure 3. Main features of the Buyukcekmece landslide, and the measurement locations acquired on the landslide.

\section{Geophysical measurements}

The geophysical studies performed on the Buyukcekmece landslide area consist of seismic measurements (P-wave refraction, MASW and ReMi) at 32 profiles, noise measurements at 37 points, and resistivity measurements at 4 profiles. The locations of all the measurements are shown in Figure 3. Because a large part of the region is still used for agricultural activity, the land surface is usually too loose to provide healthy coupling between sensor and soil. In addition, highly rugged topography of the study area makes spreading continuous profiles 
difficult. Therefore, it was generally preferred the causeways for the measurement locations, because they are built from a little bit compressed materials. On the other hand, as stated by Jongmans and Garambois (2007), the strongly disturbed and heterogeneous soil in the landslide area cause to seismic waves attenuate very fast. The energy produced by hammer source does not generally reach to the last geophones on the profiles, especially for long ones designed to increase investigation depth. We encountered with this problem in particular Pwave refraction measurements.

Seismic experiments, which include P-wave refraction, MASW and ReMi measurements, were performed on the same profiles. DoREMi equipment was used in the seismic measurements. The length of profiles was $69 \mathrm{~m}$ with 24 geophones $(4.5 \mathrm{~Hz})$ spaced by $3 \mathrm{~m}$ apart (Fig. 4). The orientation of the profiles was mostly selected perpendicular to the landslide major axis, that means N-S direction in Figure 3, in this case the slope over the layout did not change significantly. Site by site data acquisition was preferred rather than ensuing measurements due to field conditions. After that, the 2D horizontal and vertical slices were obtained from the interpolated data in the volumetric field. In the active source experiments (Refraction and MASW), the signal was generated by a $5 \mathrm{~kg}$-sledgehammer by using 3 and $6 \mathrm{~m}$ offsets. Three shots were performed at each measurement profile; two shots were located at the ends of the profiles and the other one was in the middle of the profile. Figure 4 shows the raw seismic traces for the reciprocal shots acquired at the location 10 . SeisImager code (www.geometrics.com) was used in the analyses of the seismic data. Figure 4 simply shows the analysis steps for the Refraction and MASW data. The details of analyses are given in the results section. In the ReMi measurements, it was recorded ambient noise with a duration of 5 minutes totally. It is known that, in linear ReMi arrays, seismic velocities are affected from the directivity of seismic sources, so we tried to stay away man-made noise sources during the ReMi measurements.

Guralp 6T velocity sensor (semi broadband with 30 second period) was used for the microtremor measurements. The record durations were 50 minutes in general with a sampling frequency of $100 \mathrm{~Hz}$. In addition, we took 24-hour record at 7 sites to control noise content throughout day. Most of the measurement sites are located on landslide, so they are in some degree away from human activities. However, as will be mentioned later, they include significant monochromatic vibrations likely caused by industrial sources. The Horizontal-toVertical Spectral Ratio method (H/V) is used to determine the resonance frequency of the soft layer (Nakamura, 1989). The analyses were carried out with Geopsy code (www.geopsy.org). 
Firstly, it was chosen time windows for the analyses with the length of $50 \mathrm{~s}$ and excluding strong transients from the records, and then it was computed Fourier spectra for three components smoothed with a Konno-Ohmachi windowing with a "b" value of 20 . Lastly, the $\mathrm{H} / \mathrm{V}$ values for each window were calculated as the ratio between the vector summation of the Fourier spectra of horizontal components and the spectrum of the vertical component.

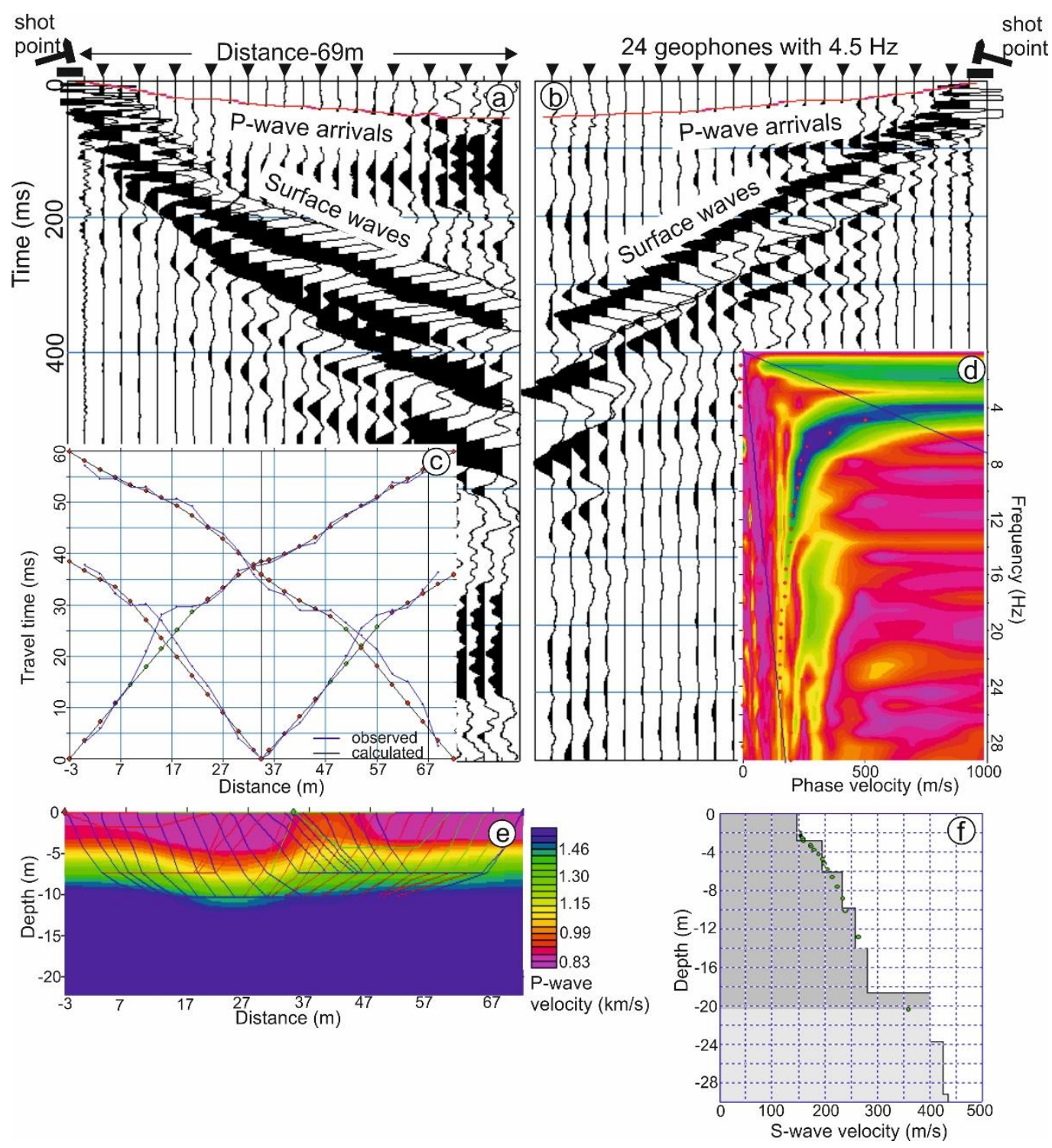

Figure 4. $a$-b) Raw seismic traces for the reciprocal shots acquired at the location 10. Shot geometry, first arrivals of $P$ wave and surface wave groups are marked on the seismic traces. 

inversion of $P$ wave velocity. $f$ ) Inversion of the $S$-wave velocity.

230 On the other hand, resistivity measurements are widely used in the landslide studies. 231 Unfortunately, in this study the resistivity measurements remained too limited due to some instrumental problems, which is manufactured by a local company, so we could perform just on the four profiles. Resistivity measurements (Vertical Electrical Soundings-VES) were made with a four electrode configuration commonly referred to as the Schlumberger array. The method uses four in-line electrodes; the inner pair for recording electrical potential as a current is passed through the outer pair. Measurements are made in a series of readings involving successively larger current electrode separations. The data are plotted on a logarithmic scale to produce a sounding curve representing apparent resistivity variations as a function of half current-electrode separation $(\mathrm{AB} / 2)$. The details of analyses are given in the results section.

\section{Results}

\subsection{Seismic measurements}

243 In the refraction analyses, at the beginning an initial layer model is established by time-term inversion for 2-layer situation relied on the slope of the lines connecting the first arrivals. After that, a tomographic inversion is performed for each profile through iterative modification of the initial model. The initial model is iteratively modified to 10 -layer model constrained by the maximum and minimum velocities of the time-term inversion. A misfit value (RMS) lower than $\% 5$ for the layer velocities is usually obtained after 10 iterations. The tomography results are controlled for the lateral changes along the profile, and it is obtained a velocity-depth profile representing that site. The velocity values at all sites are interpolated by the Kriging method, and then the horizontal slices at different depths are obtained. P-wave velocity images at depths of 2 m, 5 m, 10 m, and $20 \mathrm{~m}$ are shown in Figure 5. The maximum investigation depth in the analyses is less than $20 \mathrm{~m}$. The images of P-wave velocities do not present a notable discrimination horizontally to be correlated with the boundary of landslide mass or failure surface. The velocities range from $300 \mathrm{~m} / \mathrm{s}$ at the surface to $2400 \mathrm{~m} / \mathrm{s}$ at the bottom. The high P-wave velocities are particularly seen on the southern and the northwestern parts of the study area corresponding to the earth flow and the stable ridge, respectively. 
$\mathrm{m} / \mathrm{s}$ at depths higher than 5-10 $\mathrm{m}$ pointing out the saturated sands and clays of Cukurcesme and Danismen Formations. It is difficult to mention from any slip surface, but the highvelocity contrast and the presence of water may point out the local slides at shallow.

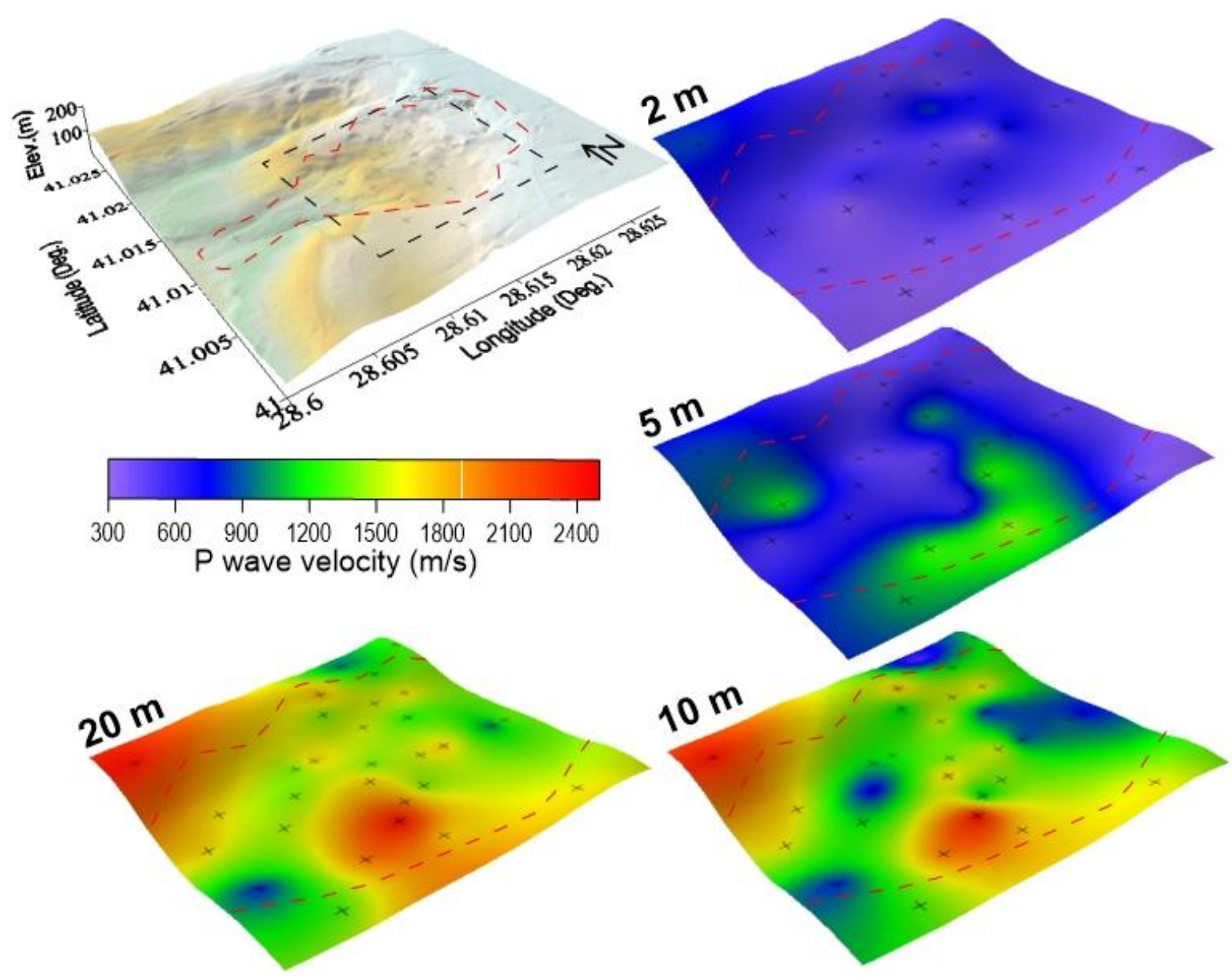

Figure 5. P-wave velocity images of the landslide area at different depths. Red and black dashed lines show the landslide boundary and the image location on the 3D map, respectively. Cross sign shows the locations of measurement sites.

Figure 6 also shows some samples of S-wave velocity-depth profiles obtained from the analyses of MASW, ReMi and the combination of them. As shown in the figure, the penetration depth for the MASW measurements is maximum $30 \mathrm{~m}$, whereas it reaches up to $80 \mathrm{~m}$ for the ReMi measurements because, as known, ambient noise data generally include 272 longer period waves than that of produced by active source. In result, in combined analyses of 273 MASW and ReMi, the high frequency parts of the dispersion curves, which also mean shallow depths less than $30 \mathrm{~m}$, consist of MASW data, whereas the low frequency parts of the 
dispersion curves, which mean deeper parts more than $30 \mathrm{~m}$, consist of ReMi data. We prefer to use multiple layers (exactly 15 layers) in the modeling of the dispersion curves in order to avoid an unreal contrast by selecting far less number of the layers.

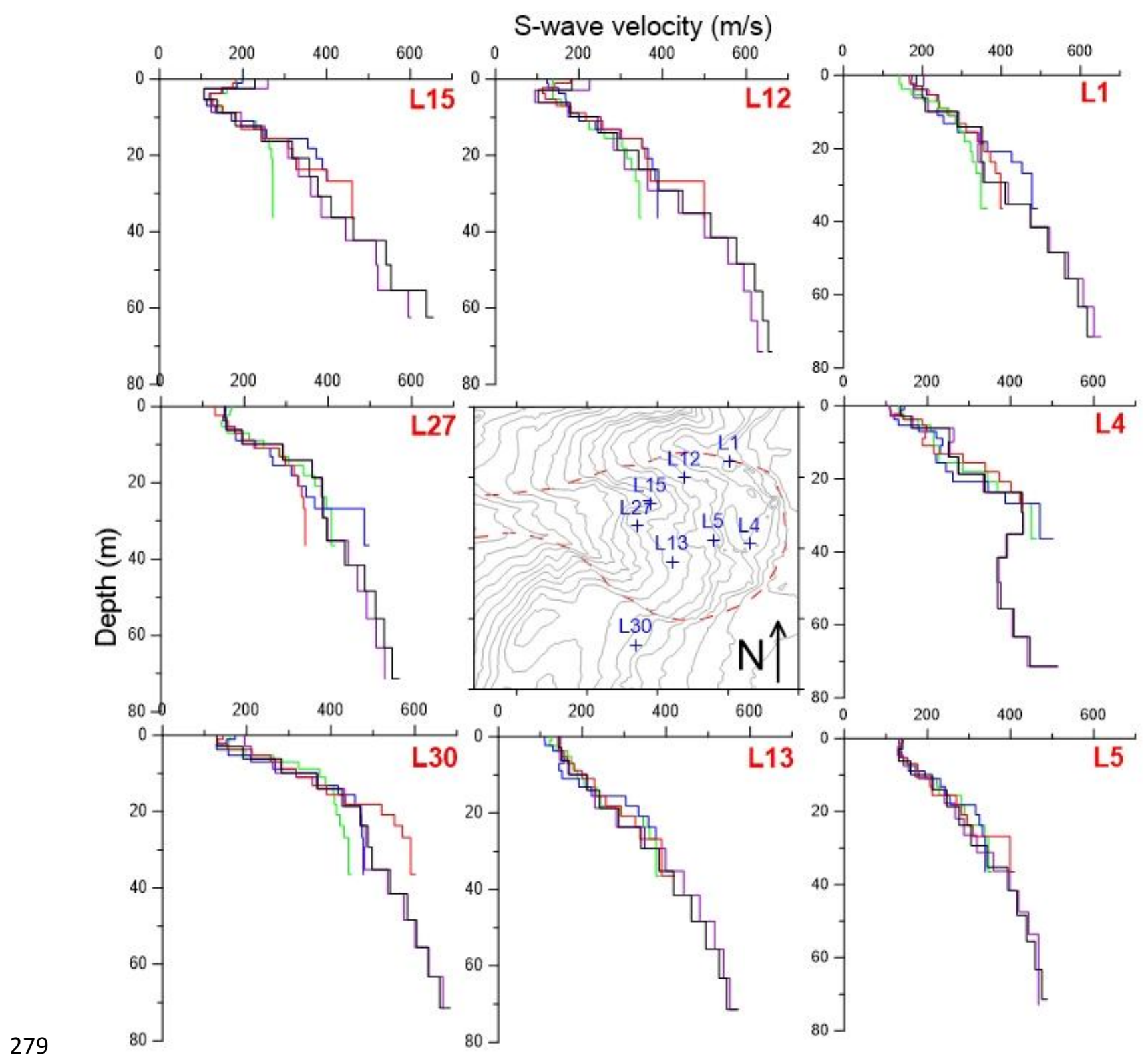

Figure 6. The depth sections of S-wave velocity at sample measurement points. Green, blue and red lines represent the results of MASW measurements for three shots performed at the two ends and in the middle of each profile. The purple lines show the results of the ReMi analysis, and the black lines represent the results of the combine analysis of MASW and 
A general result from the $\mathrm{S}$-wave velocity profiles is that the velocities do not present distinct contrasts, which would be interpreted as failure surface. In general, the velocities gradually increase as depth increases. However, the images of S-wave velocity shown in Figure 7 provide some clues related with the geometry of landslide. The S- wave velocities are very low about $100-200 \mathrm{~m} / \mathrm{s}$ in the top layer, and they increase up to $800 \mathrm{~m} / \mathrm{s}$ at the depth of $80 \mathrm{~m}$. Note that the S-wave velocities are generally lower within the boundary of landslide with respect to the surrounding area. The vertical cross sections of S-wave velocities shown in Figure 8 could be more convenient to interpret the geometry of landslide. The layers with the S-wave velocity lower than $400 \mathrm{~m} / \mathrm{s}$ take place in the middle part of the sections as compatible with the surface boundary of the landslide. The thicknesses of those layers are about 50-60 $\mathrm{m}$ in the middle parts, but change in both transverse and longitudinal direction. The layers with $500 \mathrm{~m} / \mathrm{s}$ or higher velocities extend from the bottom of moving mass to the edges of the landslide area considered as stable parts. In other words, in deeper parts than 60 $\mathrm{m}$, the S-wave velocities begin to be the same for the entire field. So, this depth can be interpreted as the bottom boundary of the landslide mass.

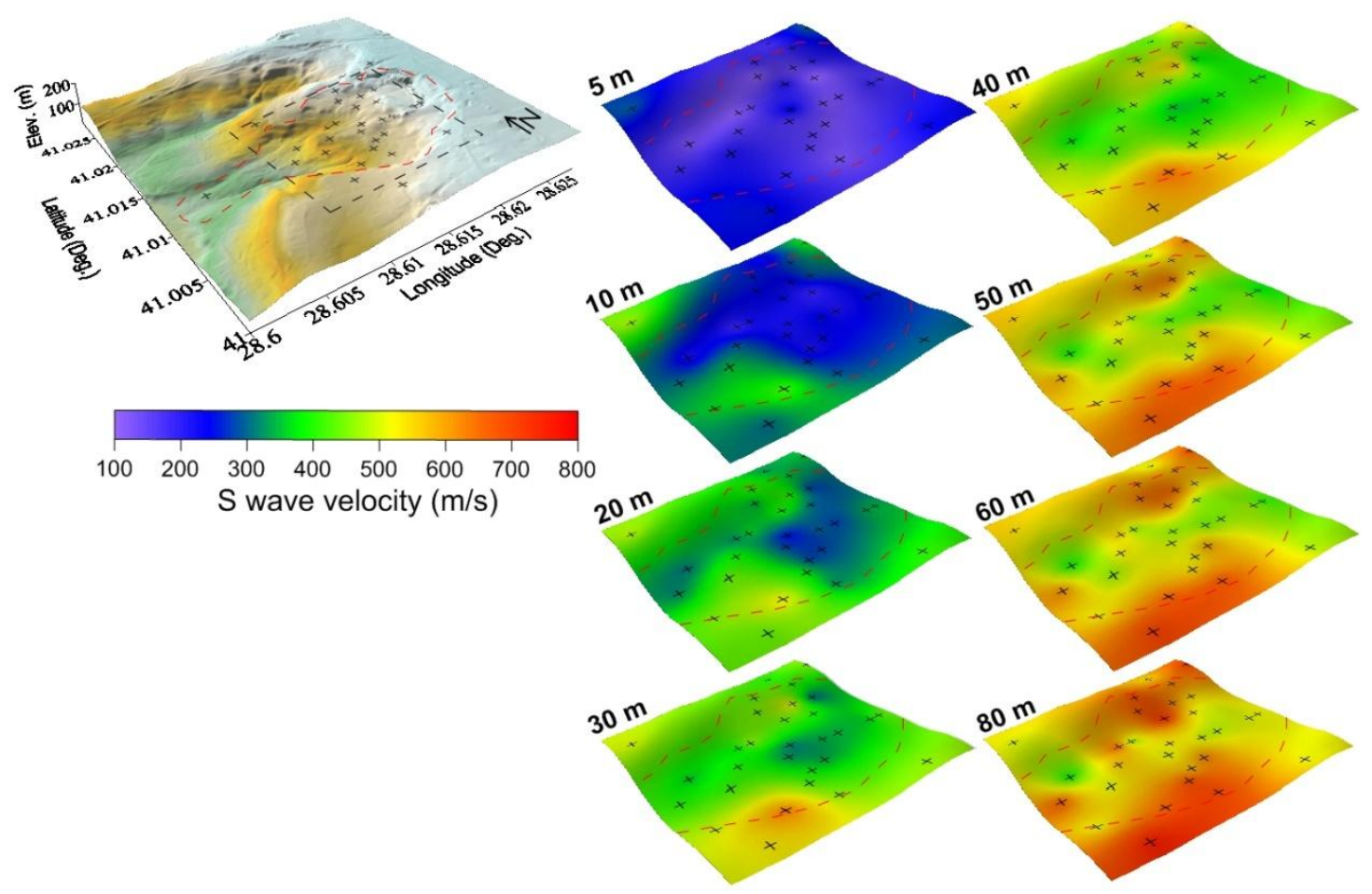


Figure 7. The S-wave velocity images at different depths. Red and black dashed lines show the landslide boundary and the image location on the 3D map, respectively. Cross sign shows
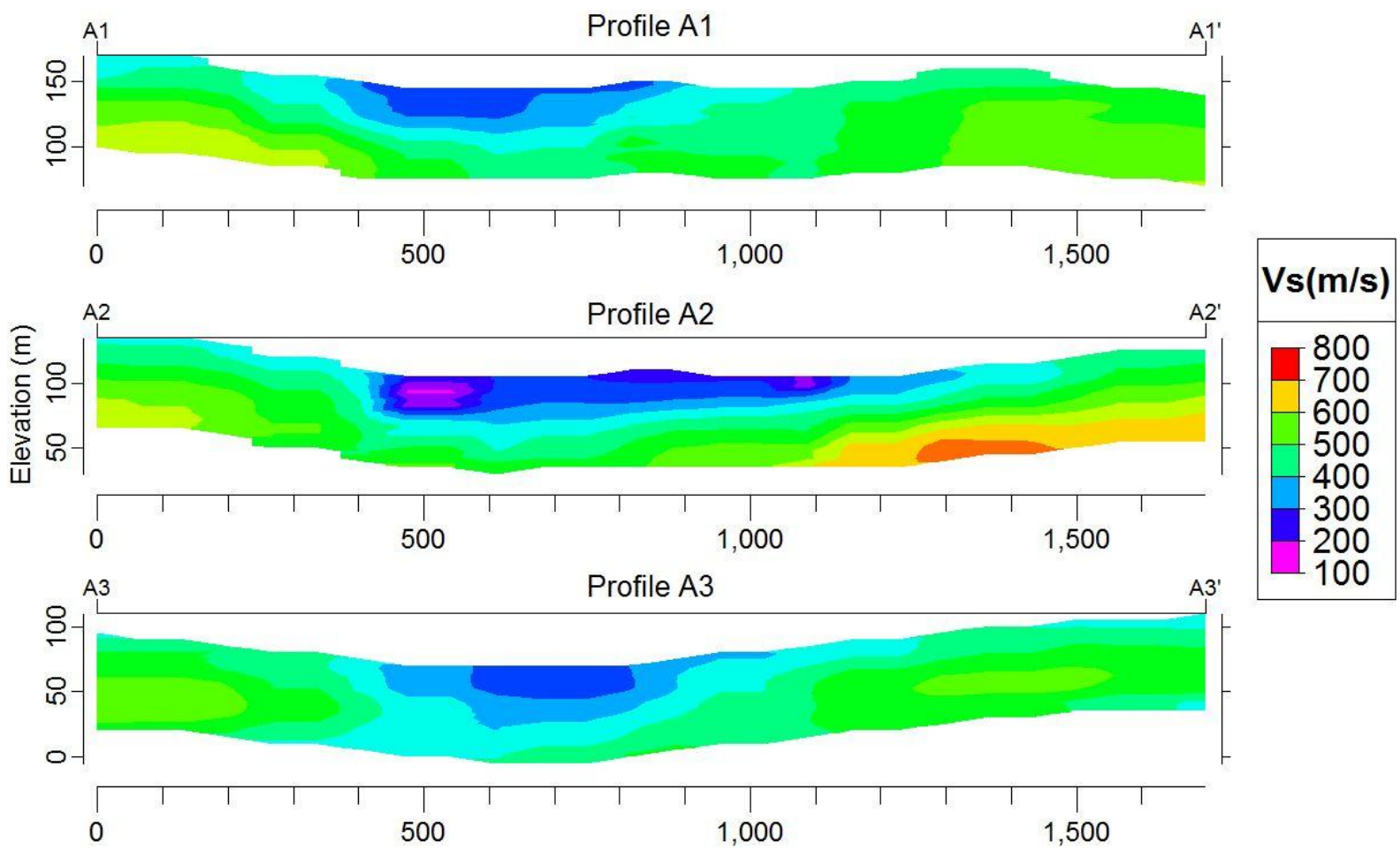

Figure 8. 2D cross sections of $S$-wave velocity. Locations of profiles A1, A2 and A3 match with the locations of sections T1, T2 and T3, respectively, shown in Figure 13.

\subsection{Noise measurements}

312 Figure 9 shows the distribution of the site resonance frequencies obtained from the $\mathrm{H} / \mathrm{V}$ analysis together with examples of several $\mathrm{H} / \mathrm{V}$ graph. It is to say that to decide resonance frequencies on the H/V curves are very difficult. One of the reasons of this is that the ambient noise records contain some anthropogenic vibrations, which are likely generated by industrial machines working in the region. The fundamental mode frequency of these vibrations is about $1.5 \mathrm{~Hz}$ (e.g. the first peak of M8 site in Figure 9), and they cause a false resonance frequency or they mask a real resonance frequency at some sites. The anthropogenic peaks were identified in three different ways; the sharp peaks on the Fourier spectra, the continuous and 
321 Figure 10 shows the identification of anthropogenic peak at $1.5 \mathrm{~Hz}$ at M8 site. The 322 anthropogenic peaks in the noise measurements are beyond the scope of this paper, but a 323 similar investigation can be found in Yalcinkaya et al. (2013). In the analyses, we tried to 324 keep away from the industrial peaks while determining the resonance peak of the H/V curve. 325 If there is no peak in he H/V curve another from the anthropogenic peak, then we kept that 326 site as undetermined. Another reason is that a number of sites in our measurements do not 327 present a clear resonance peak (e.g. M22, M29 sites in Fig. 9) as defined in the SESAME 328 project (Bard and SESAME Team, 2005). At these sites, the resonance frequencies are 329 determined by comparing the H/V curves with those of neighboring sites showing clear peak 330 assuming that the resonance frequency should not change in a few 10 meters, but peculiar 331 conditions for that site, e.g. anthropogenic vibrations or data acquisition, may prevent to see a 332 clear peak. 

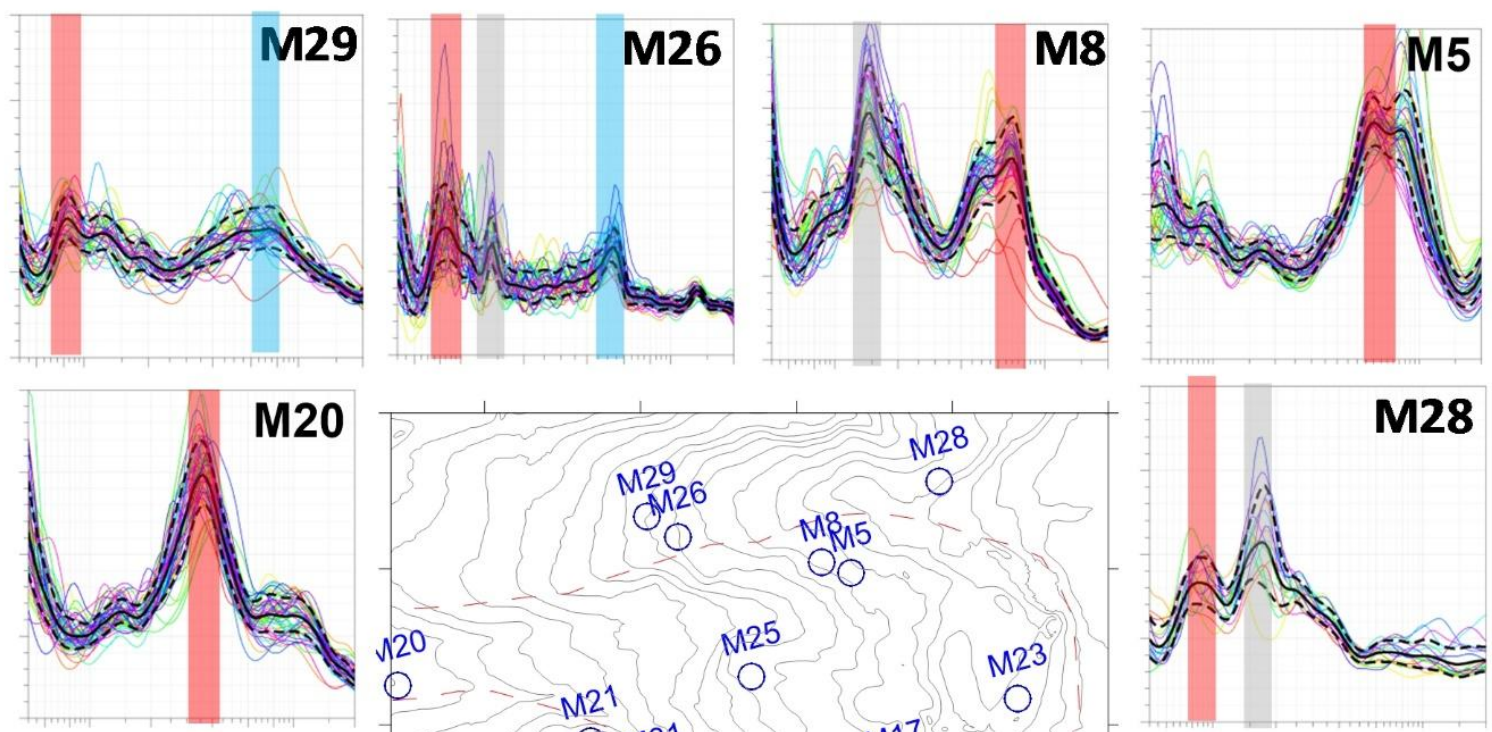
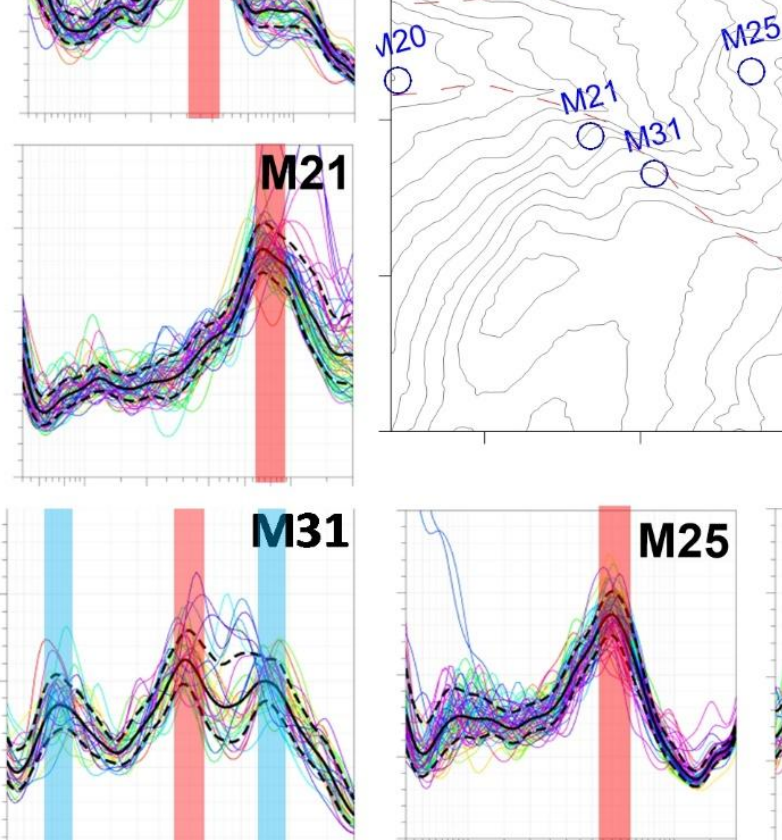

125

0

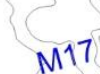

M23

0
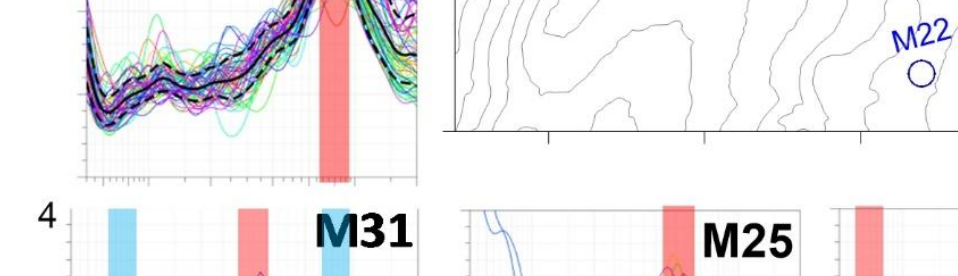

조2

333
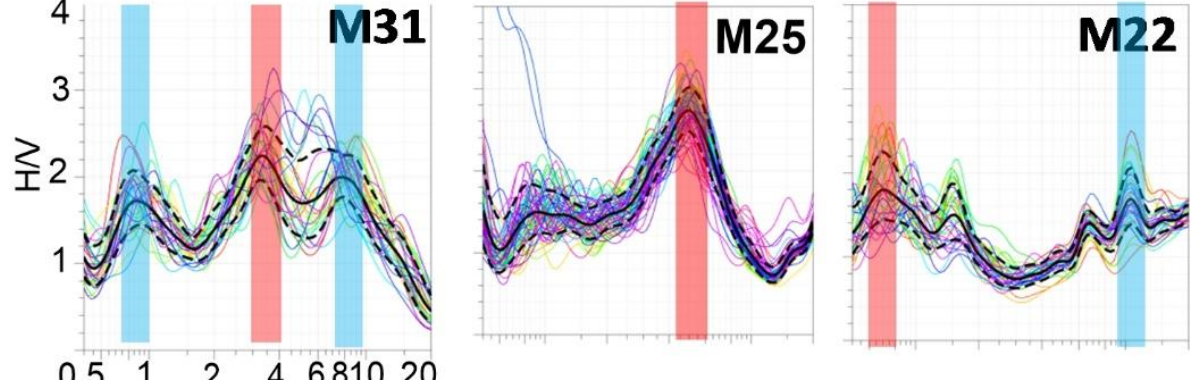
Frequency $(\mathrm{Hz})$
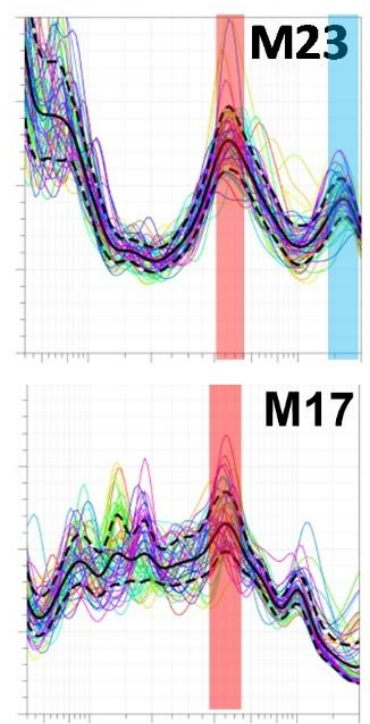


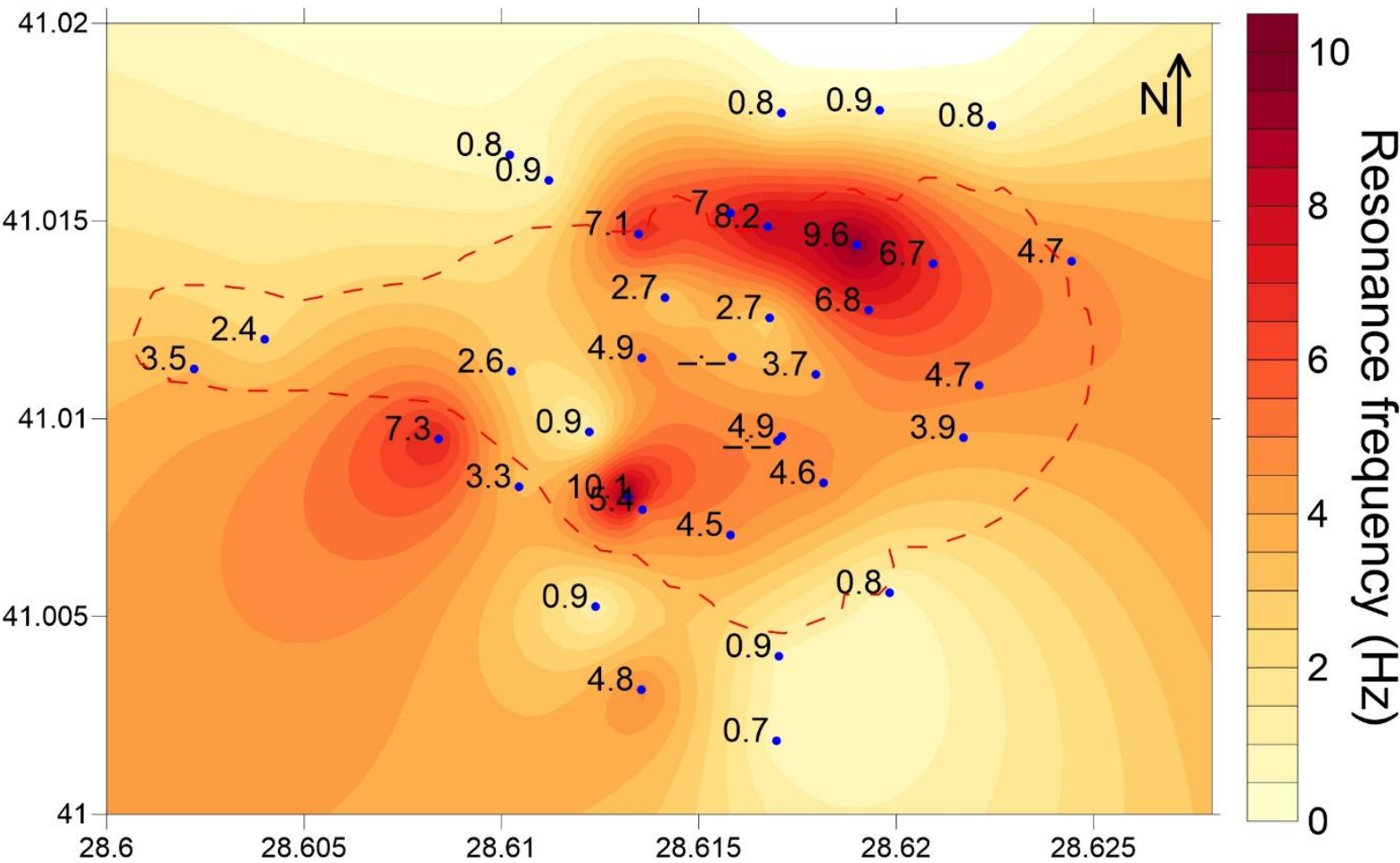

Figure 9. Upper graph represents the examples of $H / V$ curve. Measurement locations are shown on the map in the middle part. The red, blue and grey bars on the $H / V$ curves mark fundamental resonance frequencies, secondary peak frequencies and anthropogenic peaks, respectively. Bottom graph shows the counter map of site resonance frequencies. Numbers show the resonance frequency at each measurement site.
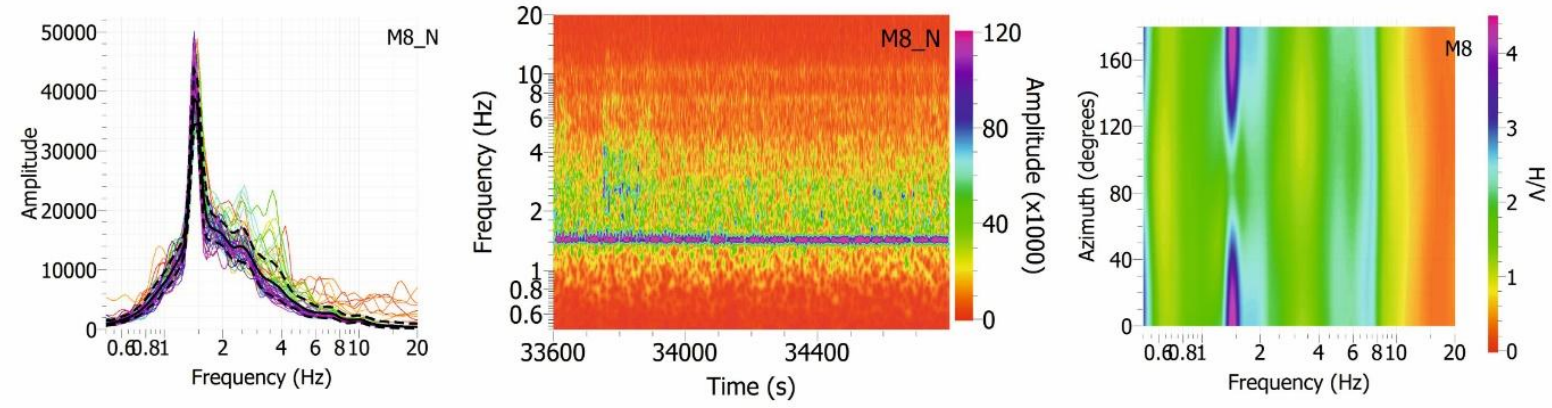

Figure 10. Identification of anthropogenic peak at $1.5 \mathrm{~Hz}$ of site M8. Fourier spectrum of NS component (on the left) exhibits a sharp peak at $1.5 \mathrm{~Hz}$. This peak has continuous and equal amplitudes on the time-frequency spectrum (in the middle). The peak at $1.5 \mathrm{~Hz}$ observed on 
As shown in Figure 9, the resonance frequencies of the sites located within the landslide mass are generally higher than those located outside of landslide. In the middle part of landslide area, the resonance frequencies are observed between $2.7-4.9 \mathrm{~Hz}$, whereas at the sites in the stable area the values decrease to $0.7-0.9 \mathrm{~Hz}$. In addition, high resonance frequencies of 6-10 $\mathrm{Hz}$ are also observed at some transition sites between landslide mass and stable area. The amplitudes of the resonance frequencies especially in the stable area are very small indicating a weak impedance contrast (e.g. M22, M26, M29 sites in Figure 9). Moreover, the H/V curves in the stable area mostly present some secondary peaks at high frequencies, which are likely produced by local slides (e.g. M22, M26, M29, M31 sites in Figure 9). This differentiation of resonance frequencies in the study area is thought that the landslide mass may be generating specific vibration resonance apart from the actual soil resonance. It is encountered similar results in the literature (e.g. Gallipoli et al., 2000; Meric et al., 2007; Jongmans et al., 2009).

The resonance frequencies $\left(f_{r}\right)$ of the $\mathrm{H} / \mathrm{V}$ curves can be converted to soil thicknesses $(H)$ by using empirical relations. Birgoren et al. (2009) suggests a relationship $\left(H=150.99 f_{r}^{-1.1531}\right)$ between soil thickness and resonance frequency for the Istanbul region. The soil thicknesses computed from the Birgoren's empirical relation are shown in Figure 11. It is seen that the thickness of the landslide mass ranges from 17 to $50 \mathrm{~m}$, and from 10 to $17 \mathrm{~m}$ on the edges of the landslide. On the stable part, i.e. outside the landslide mass, the soft soil thickness over a seismic bedrock reaches $170-228 \mathrm{~m}$, pointing out a lithological change in deeper deposits. It is also seen a few site, e.g. $170 \mathrm{~m}$ depth in the landslide mass and $25 \mathrm{~m}$ in the stable area, which do not comply with this interpretation.

A borehole was drilled by the TUBITAK (The Scientific and Technological Research Council of Turkey) in the landslide area in the framework of the MARSite project (D62 in Figure 11). Actually, a more comprehensive borehole study on the landslide area has been going on by Istanbul Municipality and TUBITAK, but their results have not been appeared yet. Figure 11 reports the borehole log-stratigraphy, as well. As shown in this log, two failure surfaces have been encountered by the borehole. The depths of the sliding surfaces are about at $30 \mathrm{~m}$ and at $50 \mathrm{~m}$, which are not so different from the depths obtained by the resonance frequencies. 


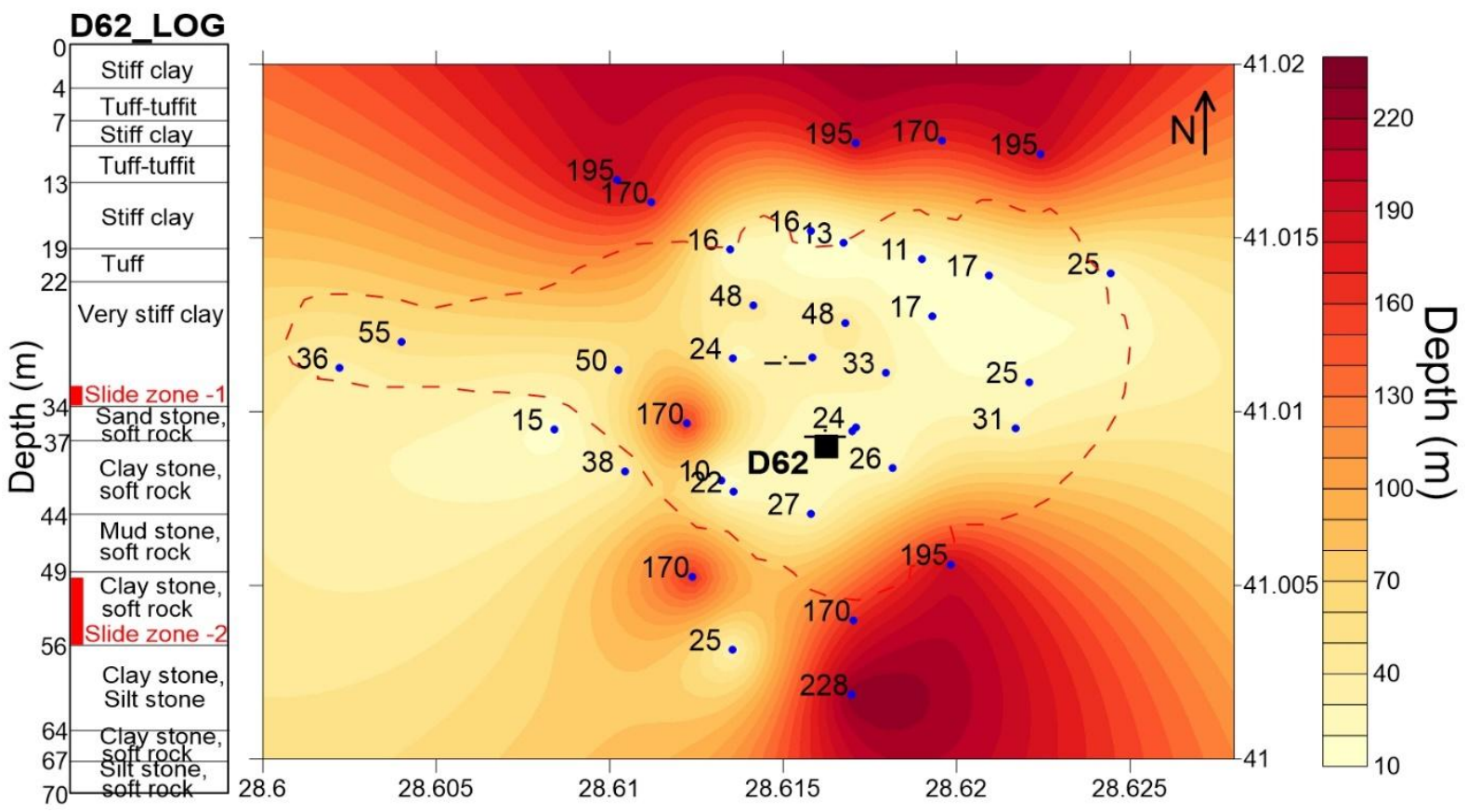

376

Figure 11. The counter map of soil thicknesses computed from resonance frequencies by the empirical relation of Birgoren et al. (2009). Numbers show the soil thicknesses at each measurement site. It is also shown a lithological section obtained from a borehole shown its location with square on the map.

\subsection{Resistivity measurements}

During the Schlumberger resistivity measurements, the electrode spacing was started from 5 $\mathrm{m}$ for the current electrodes $(\mathrm{AB} / 2)$, and $1 \mathrm{~m}$ for the potential electrodes $(\mathrm{MN} / 2)$. The current was injected to the earth ranging from $50 \mathrm{~mA}$ to $150 \mathrm{~mA}$. The maximum $\mathrm{AB} / 2$ spacing could be applied $120 \mathrm{~m}$ for the VES1 and VES3 profiles, $170 \mathrm{~m}$ for the VES2, and $65 \mathrm{~m}$ for the VES4 (Figure 12). Terrain conditions and instrumental deficiencies did not let larger spacing, so the reliable investigation depths ranged from 30 to $70 \mathrm{~m}(\sim \mathrm{AB} / 4)$. The measurements could not be interpolated to 2D-resistivity sections due to lack of enough measurements, as is done for seismic measurements. Thus, these measurements provided just 1D resistivity depth profiles at a few locations. The analyses of the resistivity measurements are shown in Figure 12. Firstly, noisy resistivity values were manually smoothed, and then the data were interpreted by using the curve matching technique. IPI2WIN software (http://geophys.geol.msu.ru/) was used to invert each sounding curve to a one-dimensional layered model. It was performed RMS-errors lower than 5\% using ground models with 4 to 6 layers relied on the bends of resistivity curve. VES1 and VES2 profiles show very low resistivity values lover than $30 \mathrm{ohm}-\mathrm{m}$ along the depth-section, i.e. a typical value for 
remolded clayey debris. These locations take place on the earth flow located on the southern part of the landslide. On the other hand, VES3 and VES4 profiles exhibit a sharp increase of the resistivity up to $120 \mathrm{ohm}-\mathrm{m}$ at almost 20-30 m below the ground level, that may be related to the secondary failure surfaces. All profiles also show a small rise in resistivity values nearly at $10 \mathrm{~m}$ depths likely corresponding to the gravelly units.
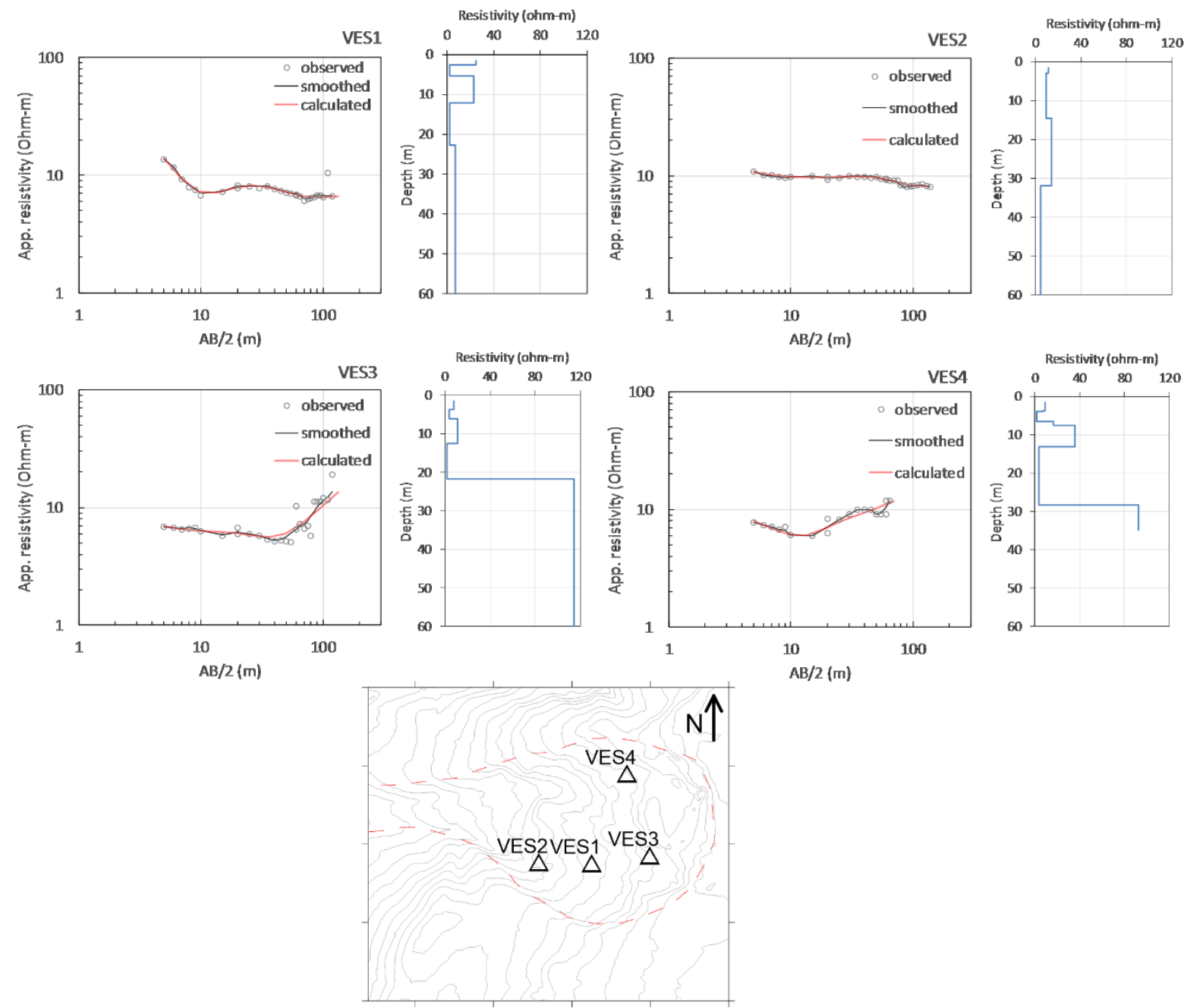

402

Figure 12. 1D ground models obtained from the analysis of resistivity measurements. The observed, smoothed and calculated resistivity values are represented with different symbols on the graphs. The profile locations are shown below on the landslide map.

\section{Discussion and conclusion} The Buyukcekmece landslide has a very complex structure, so this character complicates the exploring it by geophysical techniques. Bourdeau et al. (2016) constructed a preliminary 
model of Buyukcekmece landslide based on several geomorphological and geological

410 evidences, e.g. the borehole log stratigraphies, the geometries of the scarps, the measured dip

411 of the outcropping strata and a geometrical feedback consisting in a reversal of the present

412 landforms to reconstruct the original shape of the slope (Figure 13). In their models, the

413 landslide mass is divided into 8 blocks indicating repeated reactivations of the landslide and

414 its retrogressive evolution. The results of geophysical measurements have been interpreted

415 taking into account the geological model.
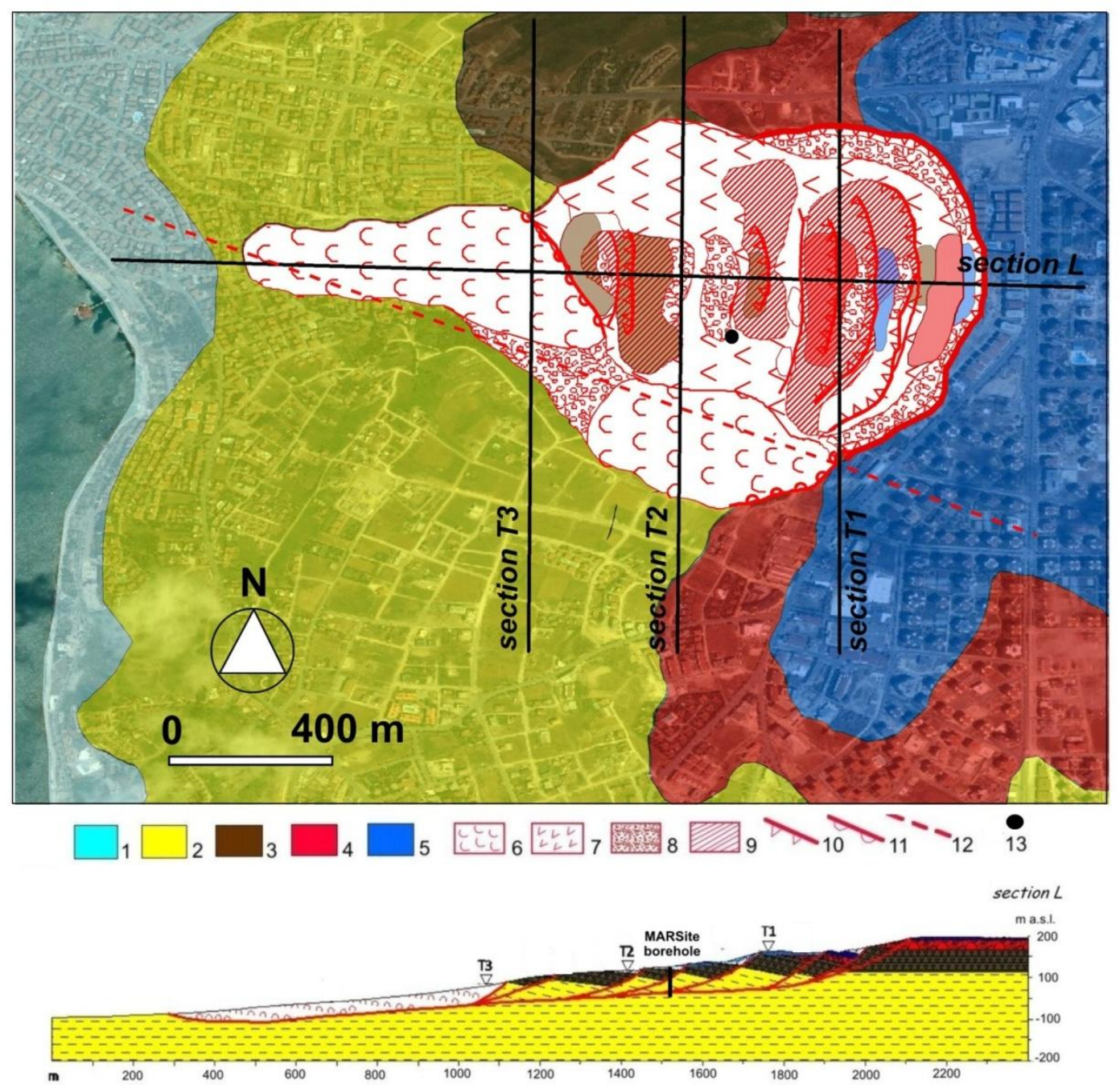

417 Figure 13. Geological map and geological cross section along trace L of the Buyukcekmece

418 landslide: 1) alluvial and coastal deposits (Holocene); 2) silty-clays of the Gungoren unit of

419 Danismen Formation (upper Oligocene); 3) clays with tuffs of the Cantakoy unit of Danismen

420 Formation (upper Oligocene-lower Miocene); 4) sands and gravels of the Cukurcesme

421 Formation (upper Oligocene-lower Miocene); 5) calcarenites of the Bakirkoy Formation

422 (upper Miocene); 6) earthflow debris; 7) rototranslational landslide mass; 8) slope debris; 

crown; 12) fault; 13) D-62 borehole. T1, T2, T3 shows the section lines shown in Figure 8.

426 The geophysical results reflect an overview of the geological model. The main slip surface of 427 Buyukcekmece landslide develops in the same geological unit consisting of the clayey layers 428 of the Danismen Formation. So, it does not constitute a strong impedance contrast between 429 the landslide mass and underlying layers. It is because of that S-waves do not exhibit 430 important velocity contrasts along the depth-profiles. In addition, the geologic strata of the 431 landslide are not so different than the surrounding area. However, it has been deforming and mixing too much due to ongoing dislocations in terms of surrounding part. The decomposing

433 of materials in the landslide causes lower seismic velocities. The analyses of S-wave velocity clearly reflect this situation. The $S$-wave velocities are lower in the landslide with respect to the stable area. This discrimination continues down to a depth of $60 \mathrm{~m}$, and then the velocities become the same for the entire area. This thickness for the landslide mass is consistent with the geological model. The material consisting of the landslide mass is a mixing of three geological units which are the Bakirkoy, Cukurcesme and the Danismen formations. The average $\mathrm{S}$-wave velocity in this complexity range from $200 \mathrm{~m} / \mathrm{s}$ to $500 \mathrm{~m} / \mathrm{s}$ from the top to the down. However, the velocities vary laterally depending on the block structure of the landslide. It is likely that some of these blocks are more stable than the others and the material consisting of it is more compact. The applied survey plan does not let us investigate each block structure. In a next survey, it should be focused on investigation of the blocks with high resolution measurements.

The complexity of the landslide structure is also evident from the P-wave velocities. The analyses of P-wave velocity did not point out a differentiation between landslide mass and stable area. A reason is that the exploration depth of the refraction analyses remains very shallow. Unfortunately, both using hammer source and strong seismic wave attenuation character of the landslide did not allow to get information from deeper parts than $20 \mathrm{~m}$. In this part, the P-wave velocities range from $300 \mathrm{~m} / \mathrm{s}$ to $2400 \mathrm{~m} / \mathrm{s}$. In general, manmade fills and slope debris on the surface have very low P-wave velocities of about $300 \mathrm{~m} / \mathrm{s}$. Toward the deeper parts, the P-wave velocity increases $1000-2000 \mathrm{~m} / \mathrm{s}$ in the stiff clays of Danismen Formation, and the sands and gravels of Cukurcesme Formation. The sandy deposits of 
Cukurcesme Formation are water-filled (Bourdeau et al. (2016). In locally, the stiff units and the presence of water may have caused to rise P-wave velocities over 1000-1500 m/s.

The fundamental frequencies of the H/V curves obtained from the microtremor measurements give the thicknesses of soil in the landslide mass between $10-50 \mathrm{~m}$ by using the empirical relation, whereas in the stable area the resonance frequencies are quite low indicating deep lithological changes in the sediments at depths of 170-228 $\mathrm{m}$. The high variability of the fundamental frequencies points out the landslide complexity. Presence of the blocks, fragmentation of the block in itself and secondary slip surfaces may have caused the variation of fundamental frequencies and additionally the secondary frequency peaks at many sites. However, the resolution of the $\mathrm{H} / \mathrm{V}$ analysis is not enough to model all of them. An interesting point is that the $\mathrm{H} / \mathrm{V}$ curves comparatively present clear site resonance peaks on the landslide mass, although S-wave velocities do not show notable contrasts. Moreover, the resonance peaks of $\mathrm{H} / \mathrm{V}$ curves do not present any dependency of azimuth as observed on some landslide cases (e.g. Burjanek et al., 2012; Del Gaudio et al., 2013).

In this study, to produce a reliable result from the resistivity analyses related with the structure of landslide is difficult but the jumping resistivity values at two profiles point out possible slip surfaces at the depths of 20 m's. The resistivity values are quite low as expected due to clayey units and water content. These results coincide with the expected structure of the landslide and the geological observations. It is worth noting that the interpretation of geophysical images needs to correlate with geotechnical investigations. It will be possible when the geotechnical investigations are completed.

Acknowledges: This study is supported by FP7 Marsite project (Grant Agreement No: 308417). We wish to thank all the members of the $6^{\text {th }}$ work package and MARSite project coordinator Prof. N.M. Ozel for their valuable contributions. We wish also thank to workers of TUBITAK-IBB project who gave support our project by providing one of their boreholes for our measurements.

\section{References}


Bard, P.Y., SESAME-Team, 2005. Guidelines for the implementation of the H/V spectral ratio technique on ambient vibrations: measurements, processing, and interpretations. SESAME European research project, EVG1-CT-2000-00026, deliverable D23.12. Available at: http://sesamefp5.obs.ujfgrenoble.fr

Barka, A., Altunel, E., Sunal, G., Cakir, Z., Dikbas, A., Yerli, B. et al., 2002. The surface rupture and slip distribution of the 17 August 1999 Izmit earthquake M 7.4 North Anatolian Fault. Bulletin of Seismological Society America 92, 43-60.

Bird, J.F., Bommer, J.J., 2004. Earthquake losses due to ground failure. Engineering Geology $75,147-179$.

Birgoren, G., Ozel, O., Siyahi, B., 2009. Bedrock depth mapping of the coast south of Istanbul: Comparison of analytical and experimental analyses. Turkish Journal of Earth Science 18, 315-329.

Bourdeau, C., Lenti, L., Martino, S., Oguz, O., Yalcinkaya, E., Bigarrè, P., Coccia, S., 2016. Comprehensive analysis of local seismic response in the complex Buyukcekmece landslide area (Turkey) by engineering-geological and numerical modelling. Engineering Geology (submitted).

Burjanek, J., Moore, J.R., Molina, F.X.Y., Fah, D., 2012. Instrumental evidence of normal mode rock slope vibration. Geophysical Journal International 188, 559-569.

Capizzi, P., Martorana, R., 2014. Integration of constrained electrical and seismic tomographies to study the landslide affecting the cathedral of Agrigento. J. Geophys. Eng. 11, doi:10.1088/1742-2132/11/4/045009.

Caris, J.P.T., Van Asch TH.W.J., 1991. Geophysical, geotechnical and hydrological investigations of a small landslide in the French Alps. Eng. Geol., 31, 249-276.

Chianese, D., Lapenna, V., Di Salvia, S., Perrone, A., Rizzo, E., 2010. Joint geophysical measurements to investigate the Rossano of Vaglio archaeological site (Basilicata Region, Southern Italy). Journal of Archaeological Science 37, 2237-2244.

Cruden, D.M., Varnes, D.J., 1996. Landslide types and processes, in Landslides: Investigation and Mitigation. A.K. Turner and R.L. Schuster (Editors), Transportation Research Board, 
511

512

513

514

515

516

517

518

519

520

521

522

523

524

525

526

527

528

529

530

531

532

533

534

535

536

537

Spec. Report 247, National Research Council, National Academy Press, Washington, DC:3675.

Dalgic, S., 2004. Factors affecting the greater damage in the Avc1lar area of Istanbul during the 17 August 1999 Izmit earthquake. Bull Eng Geol Env 63, 221-232.

Del Gaudio, V., Wasowski, J., Muscillo, J., 2013. New developments in ambient noise analysis to characterise the seismic response of landslide-prone slopes. Nat. Hazards Earth Syst. Sci.13, 2075-2087.

Duman, T.Y. et al., 2004. Istanbul Metropolu Batısındaki (Küçükçekmece-Silivri-Çatalca Yöresi) Kentsel Gelişme Alanlarının Yerbilim Verileri. Maden Tetkik ve Arama Genel Müdürlüğü (MTA) Özel Yayın Serisi - 3, Ankara.

Duman, T.Y., Can, T., Gokceoglu, C., Nefeslioglu, H.A., Sonmez, H., 2006. Application of logistic regression for landslide susceptibility zoning of Cekmece Area, Istanbul, Turkey. Environ Geol 51, 241-256.

Ergintav, S., Demirbag, E., Ediger, V., Saatcilar, R., Inan, S., Cankurtaranlar, A., Dikbas, A., Bas, M., 2011. Structural framework of onshore and offshore Avcilar, Istanbul under the influence of the North Anatolian fault. Geophys J Int 185, 93-105.

Gallipoli, M., Lapenna, V., Lorenzo, P., Mucciarelli, M., Perrone, A., Piscitelli, S., Sdao, F., 2000. Comparison of geological and geophysical prospecting techniques in the study of a landslide in southern Italy. European J. Env. Eng. Geophys., 4, 117-128.

Hack, R., 2000. Geophysics for slope stability. Surveys in Geophysics 21, 423-448.

Hubert-Ferrari, A., Barka, A., Jacques, E., Nalbant, S.S., Meyer, B., Armijo, R. et al., 2000. Seismic hazard following the 17 August 1999 Izmit earthquake. Nature 404, 269-273.

Jongmans, D., Garambois, S., 2007. Geophysical investigation of landslides: a review. Bulletin Societe Geologique de France 178 (2), 101-112.

Jongmans, D., Bievre, G., Renalier, F., Schwartz, S., Beaurez, N., Orengo, Y., 2009. Geophysical investigations of a large landslide in glaciolacustrine clays in the Trieves area (French Alps). Engineering Geology 109 (1-2), 45-56. 
Keay, S., Earl, G., Hay, S., Kay, S., Ogden, J., Strutt, K.D., 2009. The role of integrated geophysical survey methods in the assessment of archaeological landscapes: the case of Portus. Archaeol. Prospect. 16, 154-166.

King, G.C.P., Hubert-Ferrari, A., Nalbant, S.S., Meyer, B., Armijo, R., Bowman, D., 2001. Coulomb interactions and the 17 August 1999 Izmit, Turkey earthquake. Earth Planet Sci 333, $557-569$.

Lapenna, V., Lorenzo, P., Perrone, A., Piscitelli, S., Rizzo, E., Sdao, F., 2005. 2D electrical resistivity imaging of some complex landslides in Lucanian Apennine chain, southern Italy. Geophysics, 70, B11-B18.

Martino, S., Bigarrè, P., Coccia, S., Bourdeau, C., Lenti, L., Oguz, O., Yalcinkaya, E., 2016. Integrated engineering-geological and numerical approach applied to the large Buyukcekmece (Turkey) landslide for evaluating earthquake-induced effects. Landslides and Engineered Slopes. Experience, Theory and Practice - Aversa et al. (Eds), 1375-1382.

McCann, D.M., Forster, A., 1990. Reconnaissance geophysical methods in landslide investigations. Eng. Geol., 29, 59-78.

Meric, O., Garambois, S., Malet, J.-P., Cadet, H., Gueguen, P., Jongsman, D., 2007. Seismic noise-based methods for soft-rock landslide characterization. Bull Soc Geol Fr 178(2), 137148.

Nakamura, Y., 1989. A method for dynamic characteristics estimation of subsurface using microtremor on the ground surface. QR Rail Tech Res Inst 30, 25-30.

Ozgul, N. et al., 2005. İstanbul il alanının genel jeoloji ozellikleri, İBB Deprem ve Zemin İnceleme Müd., 79 pp., İstanbul.

Panzera, F., Lombardo, G., 2013. Seismic property characterization of lithotypes cropping out in the Siracusa urban area, Italy. Engineering Geology 153, 12-24.

Pondard, N., Armijo, R., King, G.C.P., Meyer, B., Flerit, F., 2007. Fault interactions in the Sea of Marmara pull apart (North Anatolian Fault): earthquake clustering and propagating earthquake sequences. Geophys J Int, doi: 10.1111/j.1365-246X.2007.03580.x

Parsons, T., Toda, S., Stein, R.S., Barka, A., Dieterich, J.H., 2000. Heightened odds of large earthquakes near Istanbul: an interaction-based probability calculation. Science 288, 661-665. 
567 Parsons, T., 2004. Recalculated probability of M C 7 earthquakes beneath the Sea of Marmara

568 Turkey. J Geophys Res 109, B05304. doi:10.1029/2003JB002667

569 Petley, D., 2010. Global patterns of loss of life from landslides. Geology 40(10), 927-930.

570 Sen, S., 2007. A fault zone cause of large amplification and damage in Avcilar (W Istanbul)

571 during 1999 Izmit earth-quake. Nat Hazards 43, 351-363.

572 Schmutz, M., Albouy, Y., Guerin, R., Maquaire, O., Vassal, J., Schott, J.-J., Descloitres, M., 573 2000. Joint electrical and time domain electromagnetism (TDEM) data inversion applied to 574 the Super Sauze earthflow (France). Surveys in Geophys., 21, 371-390.

575 Utkucu, M., Kanbur, Z., Alptekin, O., Sunbul, F., 2010, Seismic behavior of the North 576 Anatolian Fault beneath the Sea of Marmara (NW Turkey): implications for earthquake 577 recurrence times and future seismic hazard. Nat Hazards 50, 45-71.

578 Yalcinkaya, E., Tekebas, S., Pinar, A., 2013. Analysis of ambient noise in Yalova, Turkey: 579 discrimination between artificial and natural excitations. J Seismol 17, 1021-1039. 


\title{
Near-surface geophysical methods for investigating of Buyukcekmece
}

\section{landslide in Istanbul, Turkey}

\author{
Esref Yalcinkaya a, ${ }^{\mathrm{a},}$, Hakan Alpa ${ }^{\mathrm{a}}$, Oguz Ozel ${ }^{\mathrm{a}}$, Ethem Gorgun ${ }^{\mathrm{a}}$, Salvatore Martino ${ }^{\mathrm{b}}$, Luca Lenti ${ }^{\mathrm{c}}$, Celine \\ Bourdeau $^{\mathrm{c}}$, Pascal Bigarre ${ }^{\mathrm{d}}$, Stella Coccia $^{\mathrm{d}}$
}

\begin{abstract}
${ }^{a}$ Istanbul University, Engineering Faculty, Geophysical Engineering, 34320 Avcilar, Istanbul, TURKEY, eyalcin@istanbul.edu.tr

${ }^{\mathrm{b}}$ Department of Earth Sciences and Research Center for the Geological Risks (CERI) of the University of Rome "Sapienza"

${ }^{c}$ French Institute of Sciences and Technology for Transport, Development and Network (IFSTTAR-Paris)

${ }^{\mathrm{d} I N E R I S}$ Ecole des Mines des Nancy Campus ARTEM CS 14234 F-54042 Nancy Cedex France

*Corresponding author
\end{abstract}

\section{Abstract}

In this study, near surface geophysical techniques are experienced to investigate physical characteristics of the Buyukcekmece landslide (Istanbul, Turkey). The Buyukcekmece landslide has a continuous activity with a low velocity, and is classified as a complex mechanism. It includes rototranslational parts, several secondary scarps, several landslide terraces, and evidences of two earth flows. It mainly develops in the clayey layers of the Danismen Formation. According to our findings, P-wave velocities ranging from $300 \mathrm{~m} / \mathrm{s}$ to $2400 \mathrm{~m} / \mathrm{s}$ do not provide a notable discrimination between sliding mass and stable soil. They show variations in blocks reflecting complex structure. We obtained S-wave velocity structure of the landslide up to $80 \mathrm{~m}$ by combining analysis of MASW and ReMi. It is clear that Swave velocities are lower on the landslide if compared those of the stable area. Being the same of the S-wave velocities for the entire area at depths higher than $60 \mathrm{~m}$ may point out the maximum thickness of the landslide mass. Resonance frequencies obtained from the $\mathrm{H} / \mathrm{V}$ analysis on the landslide area are generally higher than those on the stable area. The depths computed by using an empirical relation between the resonance frequency and the soil thickness point out the failure surfaces from 10 to $50 \mathrm{~m}$ moving downslope from the landslide crown area. The resistivity values within the landslide are generally lower than $30 \mathrm{ohm}-\mathrm{m}$, i.e. a typical value for remolded clayey debris. The geophysical results reflect an overview of the geological model, but the complexity of landslide makes difficult the mapping of the landslide structure in detail.

Keywords: Landslide, failure surface, geophysical techniques, Buyukcekmece, earthquake, Marmara 


\section{Introduction}

The Marmara region of Turkey is getting ready for the expected Istanbul or Marmara earthquake (Fig. 1). A number of studies performed after the devastating 1999 Izmit (M7.4) and Duzce (M7.2) earthquakes characterize the Marmara fault, which is the part of North Anatolian Fault (NAF) extending under the Marmara Sea, as a seismic gap with high potential for producing large earthquake $(M>7)$ (Parsons et al., 2000; Hubert-Ferrari et al., 2000; King et al., 2001; Barka et al., 2002; Parsons, 2004; Pondard et al., 2007). A last study made by Utkucu et al. (2009) describes the Marmara region, which has imminent seismic hazard. In the region, many studies have been performing related with not only understanding of seismic hazard but also mitigation of seismic risk. The project of MARSite (New directions in seismic hazard assessment through focused earth observation in the Marmara Supersite, http://marsite.eu) is one of such study financed by European Union-FP7. It consists of 11 work packages which has a wide study range from geodetic monitoring to early warning. The $6^{\text {th }}$ work package of MARSite project, which constitutes the base of this study, focuses on the earthquake-induced landslide hazard in the Marmara region.

Earthquake-triggered landslides have an increasing disastrous impact in seismic regions due to the fast growing urbanization and infrastructures. Just considering disasters from the last fifteen years, among which the 1999 Chi-Chi earthquake, the 2008 Wenchuan earthquake, and the 2011 Tohoku earthquake, these events generated tens of thousands of co-seismic landslides. Those resulted in amazing death toll and considerable damages, affecting the regional landscape including its hydrological main features. The last seven years' recordings demonstrated that more than $50 \%$ of the total losses due to landslides worldwide are attributed to co-seismic slope failures (Petley, 2010). Moreover, as reported by Bird and Bommer (2004), the greatest damage caused by earthquakes is often related to landslides.

Besides the high level of seismic risk, landslides in Turkey constitute the second source of life and economical losses induced by natural hazards. In fact, the 1999 Izmit earthquake (M7.4) caused numerous landslides on the north part of the Marmara Sea, especially along the western shores of Istanbul. In the Marmara Region, the earthquake-triggered landslides risk is steadily increasing due to the growing "urban pressure" over landslide prone areas. Especially the Avcilar-Beylikduzu Peninsula situated between Kucukcekmece and Buyukcekmece Lakes in the westward of Istanbul (Fig. 2) is an active landslide area when considering high seismic landslide risk because of extensively constructed and rapid increase in population. In the 
Marmara region where a disastrous earthquake is expected, the earthquake-triggered landslides, their characterization and monitoring and also early warning issue are key issues in terms of public safety and disaster prevention.

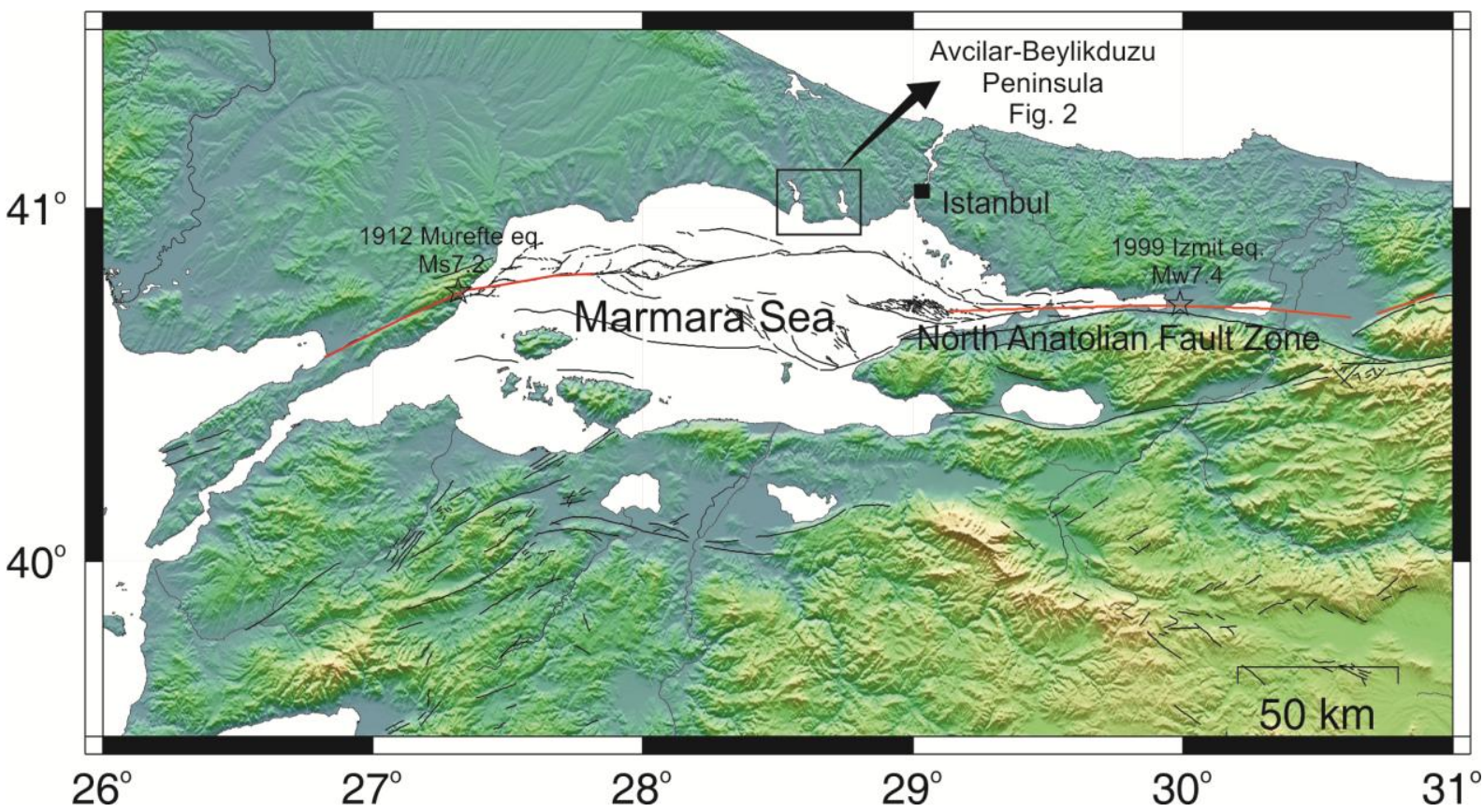

Figure 1. North Anatolian Fault Zone (NAF) extending in the Marmara Region of Turkey (black lines), and the surface ruptures of last two earthquakes occurred on the NAF (red lines).

In the last decade, near-surface geophysical techniques have been widely used for characterization of landslides (e.g. Meric et al., 2007; Jongmans et al., 2009). The applications based on that moving mass of landslide have different physical properties in terms of surrounding rock or stable soil due to exposed to deformations, fractures, water content, and porosity. There are two main targets of geophysical investigations: the first is the location of the vertical and lateral boundaries of the landslide, that is the failure surface, and the second is the mapping of the internal structure of the landslide (Jongmans and Grambois, 2007) . A boundary or contrast in properties of sub-surface layers can be readily available by geophysical methods. However, this boundary may not be always sufficiently strong to be explored by geophysical methods or the resolution of applied techniques may not adequate to locate the potential slip surface. According to McCann and Forster (1990), the success of any 
geophysical technique depends on four main controlling factors: the existence of a geophysical contrast differentiating the body to be mapped, the resolution and penetration of the method, the calibration of geophysical techniques by geological or geotechnical data and, finally, the signal to noise ratio. While the electrical and seismic methods were the most used geophysical methods in the past, the seismic noise and ground-penetrating radar measurements were added to those in the last years (Caris and Van Asch, 1991; Gallipoli et al., 2000; Schmutz et al., 2000; Lapenna et al., 2005; Meric et al., 2007). The advantage or disadvantage of a method to the others vary depending on the landslide specifications and data acquisition parameters. Using of integrated geophysical methods and inversion of geophysical data constrained by stratigraphic information allow to significantly increase reliability of geophysical models (Meric et al., 2007; Keay et al., 2009; Chianese et al., 2010; Panzera and Lombardo, 2013; Capizzi and Martorana, 2014). A broad review about the advantages and disadvantages of the geophysical techniques on the landslide characterization can be found in Hack (2000) and Jongmans and Grambois (2007). In general, low resistivity values and low seismic velocities characterize landslide body in terms of undisturbed soil. Resistivity values of landslide body in compact clays and marls decrease 10-30 $\Omega . m$ depending on weathering extent and water content, while the undisturbed soil is characterized by a resistivity over 60-75 $\Omega . m$ (Caris and Van Asch, 1991; Lapenna et al., 2005; Meric et al., 2007). Mostly strong P and S-wave velocity contrasts were found between the landslide body $\left(\mathrm{V}_{\mathrm{p}}<400 \mathrm{~m} / \mathrm{s}, \mathrm{V}_{\mathrm{s}}<300 \mathrm{~m} / \mathrm{s}\right)$ and the basement $\left(\mathrm{V}_{\mathrm{p}}>1500 \mathrm{~m} / \mathrm{s}, \mathrm{V}_{\mathrm{s}}>500 \mathrm{~m} / \mathrm{s}\right)($ Caris and $\mathrm{Van}$ Asch, 1991; Meric et al., 2007; Jongmans et al., 2009). On the other hand, the examples which these differentiations between landslide body and surrounding material cannot be monitored are also available (Jongmans et al., 2009).

This paper covers the analyses of near-surface geophysical measurements aiming to reveal the vertical and lateral boundaries of the Buyukcekmece landslide, which is chosen as pilot investigation site in the frame of $6^{\text {th }}$ work package of the Marsite Project. An additional target is the mapping of the internal structure of the landslide for the stability analyses under the seismic shaking. Geophysical results will be compared with the geological models constructed preliminary by geological and morphological observations. 


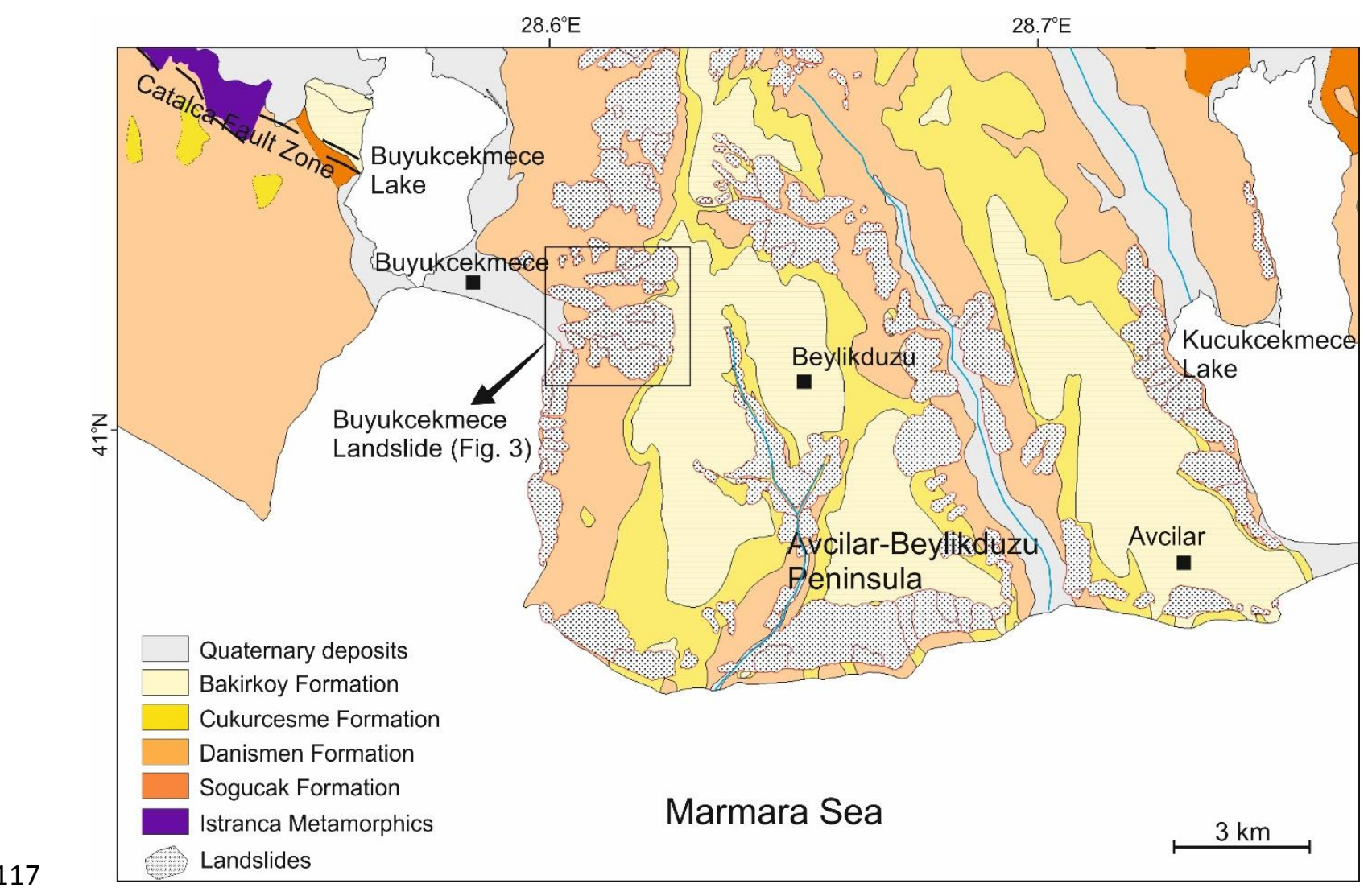

Figure 2. Landslide map and simplified geology of the Avcilar-Beylikduzu Peninsula (modified from Duman et al., 2004; Ozgul et al., 2005 and Ergintav et al., 2011).

\section{Buyukcekmece landslide}

The Buyukcekmece landslide takes place in the Avcilar-Beylikduzu peninsula in the western part of Istanbul metropolitan area (Fig. 2). The NAF passes through the distance of about 15 $\mathrm{km}$ from south of the study area. The study area is bordered by the Marmara Sea in the south. While the topography sharply increases from the sea coast to 50-100 m elevation in the south, it has a plateau character elevated gently toward to the north. This plateau is incised and dissected by river channels flowing to the Marmara Sea. Both river slopes and coastal slopes are active landslide areas. The materials attached loosely on steep slopes flow downward. Rainfall, topographic slope, human activity and seismic motions can be regarded as possible triggers for landslides in this area. While the youngest geological units take place on the top of the plateau, it is possible to see the older units on the bottom of river channels and the coastal slopes (Dalgic, 2004; Duman et al., 2006; Sen, 2007). The Avcilar-Beylikduzu peninsula is of particular interest for landslide susceptibility to earthquake triggering as: $i$ ) it 
was recently struck by the $17^{\text {th }}$ August $1999 \mathrm{Mw} 7.4$ Izmit and by the $12^{\text {th }}$ November Mw 7.2 Duzce earthquakes; ii) several rototranslational landslides were recognized with width ranging from 250 up to $1000 \mathrm{~m}$, varying between 300 and $2000 \mathrm{~m}$ in length and maximum depth of sliding surface ranging from some tens of meters up to $100 \mathrm{~m}$ (Martino et al., 2016). Among these the Buyukcekmece landslide is the biggest one with a volume of about $90 \mathrm{Mm}^{3}$; it involves several buildings, roads and infrastructures causing visible damages. It has about $1000 \mathrm{~m}$ width and $2000 \mathrm{~m}$ length (Fig. 3). Two landslide masses can be recognized in the Buyukcekmece slope, so generating a two loops morphology, as can be seen in Figure 3, the two landslide masses are divided by a ridge. The right landslide mass constitutes the investigation site. The slope on the landslide partly rises to \%24; the average is approximately $\% 10$. This landslide has a continuous activity with a low velocity; according to Cruden and Varnes (1966) it is classified as complex mechanism. It includes counterslope tilted blocks, several secondary scarps, several landslide terraces (these last ones are characterized by an evident counter slope and some of them are responsible for the presence of water pools), evidences of two earth flows; the first one located along the right side of the landslide mass and the second one at its toe (these earth flows are clearly visible in the field due to the presence of detachment and transportation zones) (Fig. 3). Several evidences of damage to roads, buildings, walls, and infrastructures were also collected and considered for mapping the landslide mass.

The geological setting of the Buyukcekmece landslide area is defined according to previous studies (Dalgic, 2004; Duman et al., 2006; Ergintav et al., 2011). The Avcilar-Beylikduzu Peninsula is located on the boundary between Istranca Metamorphics (Mesozoic), which crop out in the Catalca Fault Zone and Istanbul Unit (Paleozoic), which crops out northeast of the Kucukcekmece Lake (Fig. 2). Both are overlain by Eocene and younger sediments. The thickness of sediments under the peninsula exceeds $700 \mathrm{~m}$ according to water holes drilled in the region (Dalgic, 2004). These sediments can be divided into three main units from below to the top: the Danismen (Duman et al., 2006) or Gurpinar (Dalgic, 2004) Formation (upper Oligocene-lower Miocene) consisting of stiff clays and claystone-shales containing loose sand horizons and tuff levels of different thicknesses; the Cukurcesme Formation (Miocene) consisting of sands and gravels belonging to fluvial deposits generally poorly or not cemented with rare interbeds of tuff; and the Bakirkoy Formation (upper Miocene) consisting of alternating calcarenite, marl and clay layers. The Buyukcekmece landslide mainly occurs in the Danismen Formation including both the Gungoren and the Cantakoy units. The Bakirkoy 
Formations outcrop in the main scarp of the landslide (Fig. 2). As it is resulted from field surveys, the deposits belonging to the Bakirkoy, Cukurcesme and Danismen Formations are involved the landslide mass. Nevertheless, due to the existence of several secondary scarps the original geological setting of the deposits is significantly modified as counterslope tilted landslide blocks can be surveyed in the landslide mass area (Fig. 3).

\section{+ Seismic measurements \\ Noise measurements \\ $\triangle$ Resistivity measurements Landslide boundary Landslide scarp Landslide terrace Earth flows}

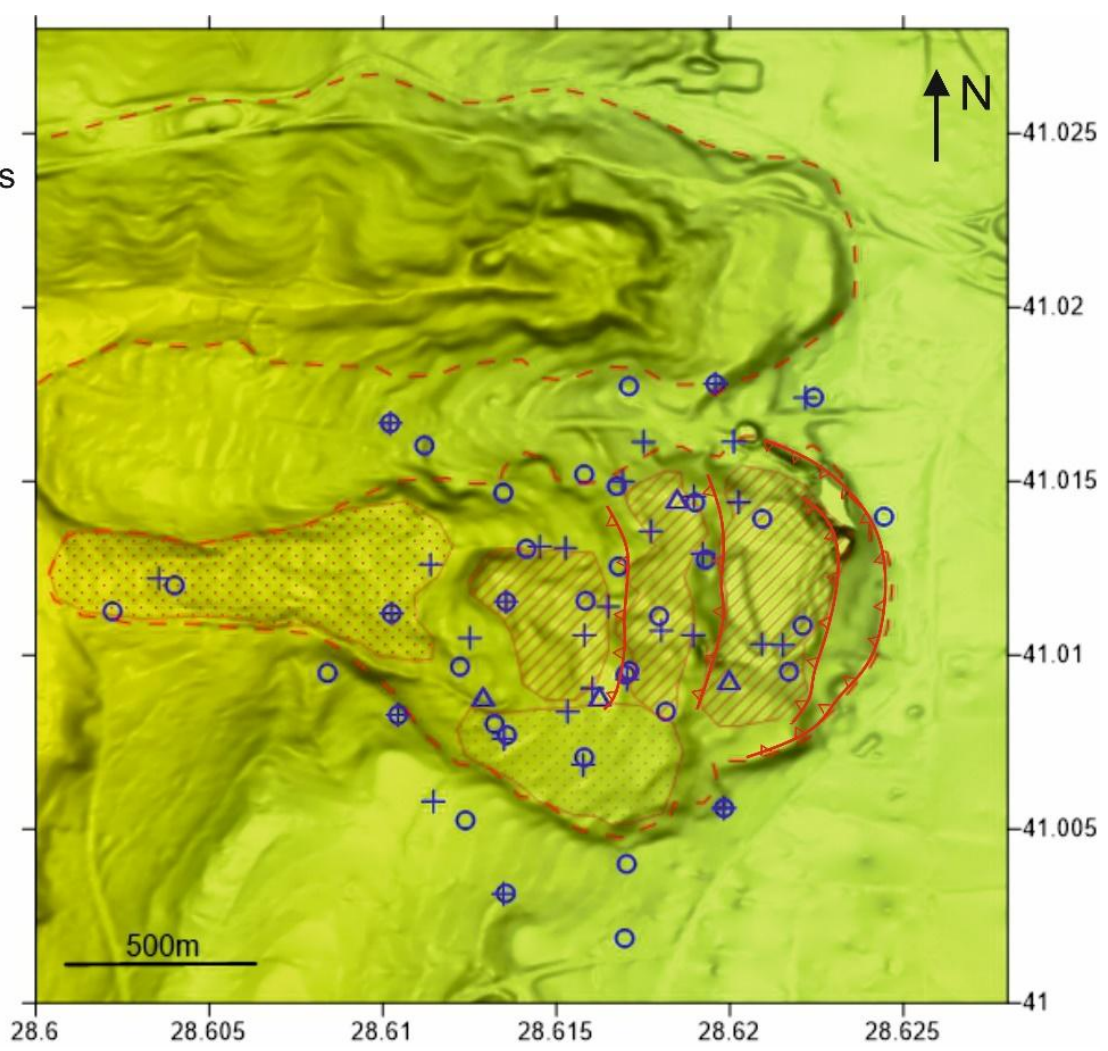

Figure 3. Main features of the Buyukcekmece landslide, and the measurement locations acquired on the landslide.

\section{Geophysical measurements}

The geophysical studies performed on the Buyukcekmece landslide area consist of seismic measurements (P-wave refraction, MASW and ReMi) at 32 profiles, noise measurements at 37 points, and resistivity measurements at 4 profiles. The locations of all the measurements are shown in Figure 3. Because a large part of the region is still used for agricultural activity, the land surface is usually too loose to provide healthy coupling between sensor and soil. In addition, highly rugged topography of the study area makes spreading continuous profiles 
difficult. Therefore, it was generally preferred the causeways for the measurement locations, because they are built from a little bit compressed materials. On the other hand, as stated by Jongmans and Garambois (2007), the strongly disturbed and heterogeneous soil in the landslide area cause to seismic waves attenuate very fast. The energy produced by hammer source does not generally reach to the last geophones on the profiles, especially for long ones designed to increase investigation depth. We encountered with this problem in particular Pwave refraction measurements.

Seismic experiments, which include P-wave refraction, MASW and ReMi measurements, were performed on the same profiles. DoREMi equipment was used in the seismic measurements. The length of profiles was $69 \mathrm{~m}$ with 24 geophones $(4.5 \mathrm{~Hz})$ spaced by $3 \mathrm{~m}$ apart (Fig. 4). The orientation of the profiles was mostly selected perpendicular to the landslide major axis, that means $\mathrm{N}-\mathrm{S}$ direction in Figure 3, in this case the slope over the layout did not change significantly. Site by site data acquisition was preferred rather than ensuing measurements due to field conditions. After that, the 2D horizontal and vertical slices were obtained from the interpolated data in the volumetric field. In the active source experiments (Refraction and MASW), the signal was generated by a $5 \mathrm{~kg}$-sledgehammer by using 3 and $6 \mathrm{~m}$ offsets. Three shots were performed at each measurement profile; two shots were located at the ends of the profiles and the other one was in the middle of the profile. Figure 4 shows the raw seismic traces for the reciprocal shots acquired at the location 10 . SeisImager code (www.geometrics.com) was used in the analyses of the seismic data. Figure 4 simply shows the analysis steps for the Refraction and MASW data. The details of analyses are given in the results section. In the ReMi measurements, it was recorded ambient noise with a duration of 5 minutes totally. It is known that, in linear ReMi arrays, seismic velocities are affected from the directivity of seismic sources, so we tried to stay away man-made noise sources during the ReMi measurements.

Guralp 6T velocity sensor (semi broadband with 30 second period) was used for the microtremor measurements. The record durations were 50 minutes in general with a sampling frequency of $100 \mathrm{~Hz}$. In addition, we took 24-hour record at 7 sites to control noise content throughout day. Most of the measurement sites are located on landslide, so they are in some degree away from human activities. However, as will be mentioned later, they include significant monochromatic vibrations likely caused by industrial sources. The Horizontal-toVertical Spectral Ratio method $(\mathrm{H} / \mathrm{V})$ is used to determine the resonance frequency of the soft layer (Nakamura, 1989). The analyses were carried out with Geopsy code (www.geopsy.org). 
Firstly, it was chosen time windows for the analyses with the length of $50 \mathrm{~s}$ and excluding strong transients from the records, and then it was computed Fourier spectra for three components smoothed with a Konno-Ohmachi windowing with a "b" value of 20 . Lastly, the $\mathrm{H} / \mathrm{V}$ values for each window were calculated as the ratio between the vector summation of the Fourier spectra of horizontal components and the spectrum of the vertical component.

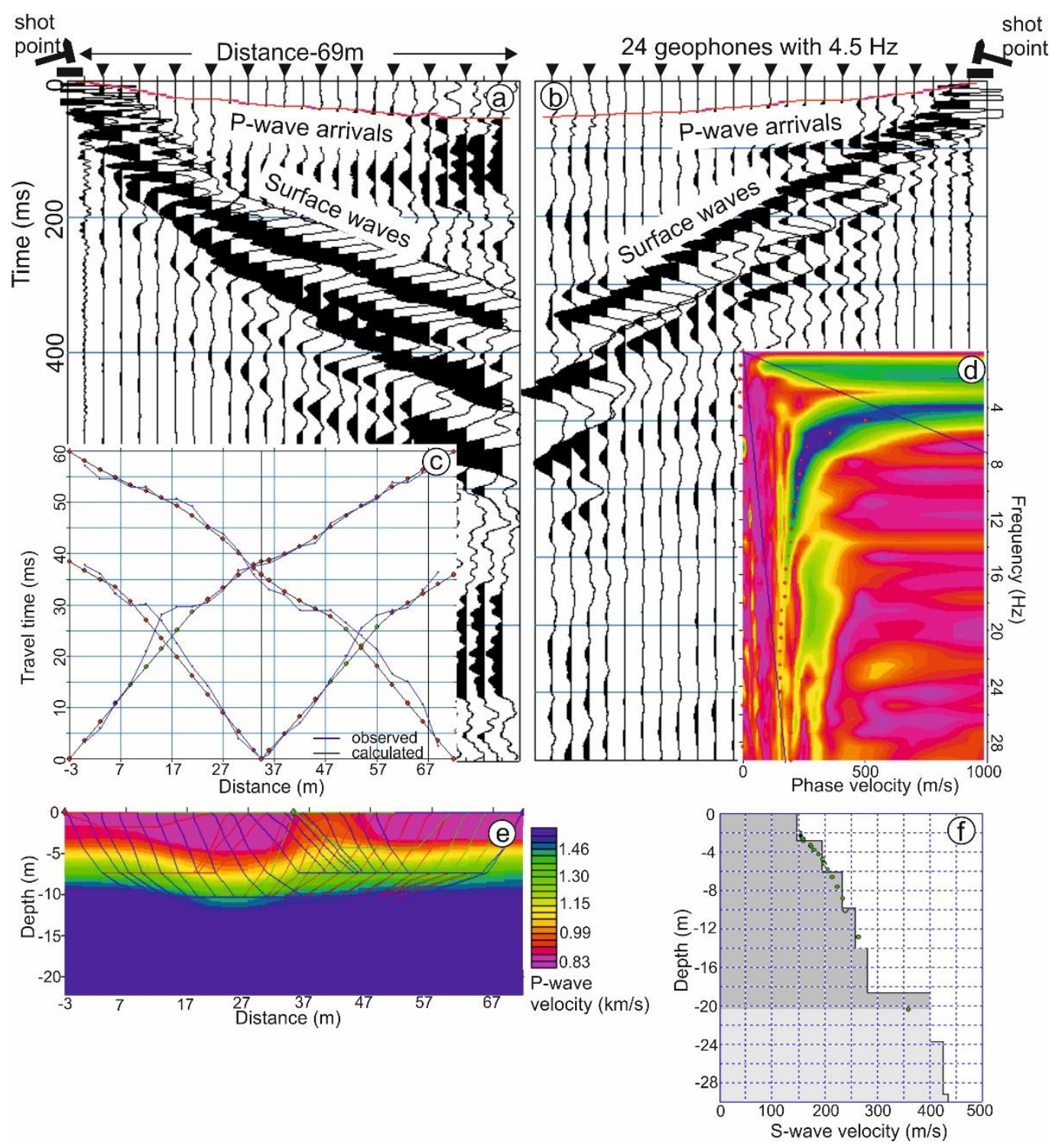

Figure 4. $a$ - b) Raw seismic traces for the reciprocal shots acquired at the location 10. Shot geometry, first arrivals of $P$ wave and surface wave groups are marked on the seismic traces.

c) Travel time versus distance graph for the three shots at $-3 m, 34.5 m$ and $72 m$. Blue and black lines show observations and calculations, respectively. d) Dispersion curve for the 
surface wave. Red dots show the marked phase velocities versus frequency. e) Tomographic inversion of $P$ wave velocity. $f$ ) Inversion of the $S$-wave velocity.

On the other hand, resistivity measurements are widely used in the landslide studies. Unfortunately, in this study the resistivity measurements remained too limited due to some instrumental problems, which is manufactured by a local company, so we could perform just on the four profiles. Resistivity measurements (Vertical Electrical Soundings-VES) were made with a four electrode configuration commonly referred to as the Schlumberger array. The method uses four in-line electrodes; the inner pair for recording electrical potential as a current is passed through the outer pair. Measurements are made in a series of readings involving successively larger current electrode separations. The data are plotted on a logarithmic scale to produce a sounding curve representing apparent resistivity variations as a function of half current-electrode separation $(\mathrm{AB} / 2)$. The details of analyses are given in the results section.

\section{Results}

\subsection{Seismic measurements}

In the refraction analyses, at the beginning an initial layer model is established by time-term inversion for 2-layer situation relied on the slope of the lines connecting the first arrivals. After that, a tomographic inversion is performed for each profile through iterative modification of the initial model. The initial model is iteratively modified to 10 -layer model constrained by the maximum and minimum velocities of the time-term inversion. A misfit value (RMS) lower than $\% 5$ for the layer velocities is usually obtained after 10 iterations. The tomography results are controlled for the lateral changes along the profile, and it is obtained a velocity-depth profile representing that site. The velocity values at all sites are interpolated by the Kriging method, and then the horizontal slices at different depths are obtained. P-wave velocity images at depths of $2 \mathrm{~m}, 5 \mathrm{~m}, 10 \mathrm{~m}$, and $20 \mathrm{~m}$ are shown in Figure 5. The maximum investigation depth in the analyses is less than $20 \mathrm{~m}$. The images of P-wave velocities do not present a notable discrimination horizontally to be correlated with the boundary of landslide mass or failure surface. The velocities range from $300 \mathrm{~m} / \mathrm{s}$ at the surface to $2400 \mathrm{~m} / \mathrm{s}$ at the bottom. The high P-wave velocities are particularly seen on the southern and the northwestern parts of the study area corresponding to the earth flow and the stable ridge, respectively. Actually, the P-wave velocities in the whole area exhibit differentiations in parts indicating the complexity of structure. On the other hand, the velocities sharply increase over 1000-1500 
$\mathrm{m} / \mathrm{s}$ at depths higher than 5-10 $\mathrm{m}$ pointing out the saturated sands and clays of Cukurcesme and Danismen Formations. It is difficult to mention from any slip surface, but the highvelocity contrast and the presence of water may point out the local slides at shallow.

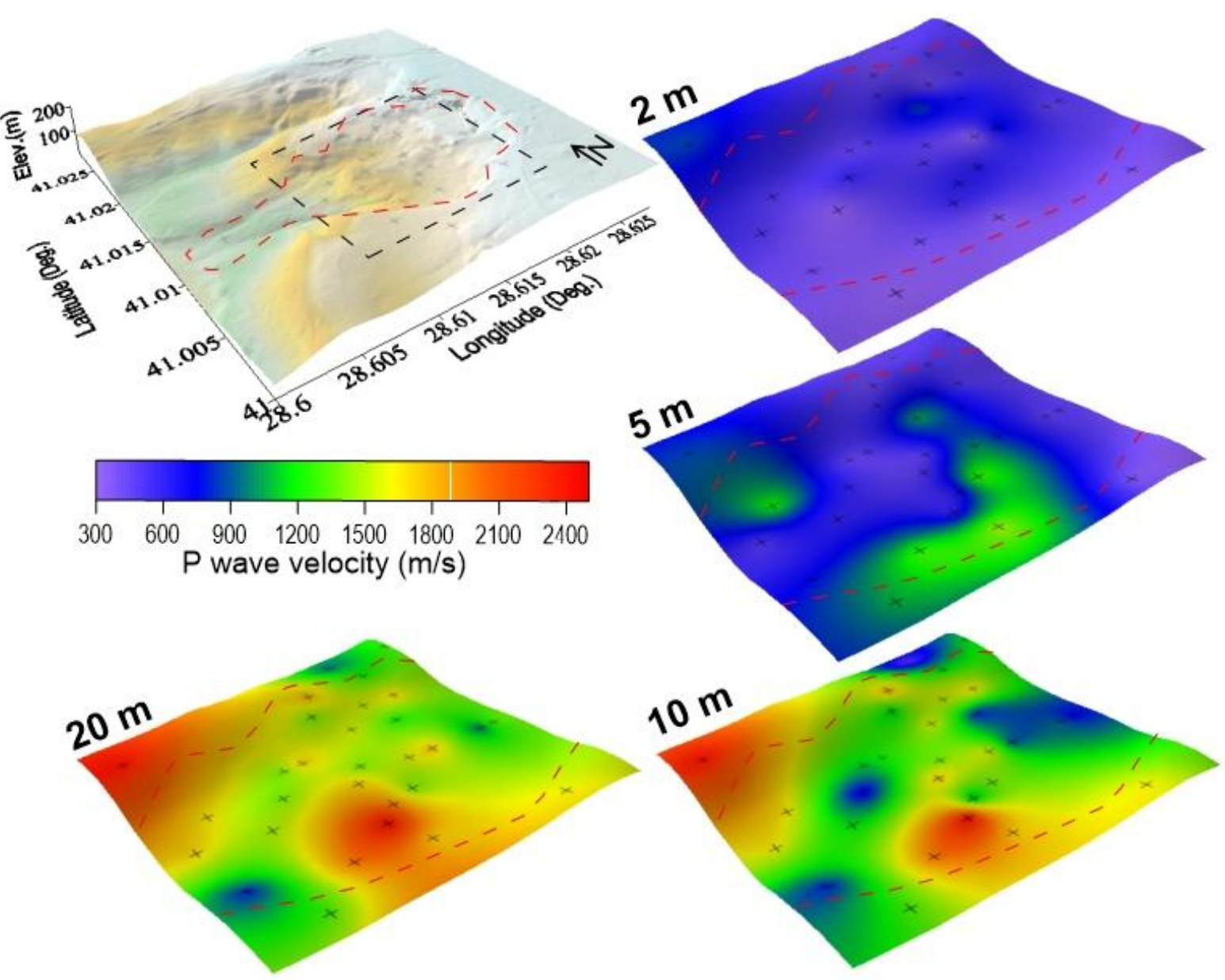

Figure 5. P-wave velocity images of the landslide area at different depths. Red and black dashed lines show the landslide boundary and the image location on the $3 D$ map, respectively. Cross sign shows the locations of measurement sites.

Figure 6 also shows some samples of S-wave velocity-depth profiles obtained from the analyses of MASW, ReMi and the combination of them. As shown in the figure, the penetration depth for the MASW measurements is maximum $30 \mathrm{~m}$, whereas it reaches up to $80 \mathrm{~m}$ for the ReMi measurements because, as known, ambient noise data generally include longer period waves than that of produced by active source. In result, in combined analyses of MASW and ReMi, the high frequency parts of the dispersion curves, which also mean shallow depths less than $30 \mathrm{~m}$, consist of MASW data, whereas the low frequency parts of the 
dispersion curves, which mean deeper parts more than $30 \mathrm{~m}$, consist of ReMi data. We prefer to use multiple layers (exactly 15 layers) in the modeling of the dispersion curves in order to avoid an unreal contrast by selecting far less number of the layers.

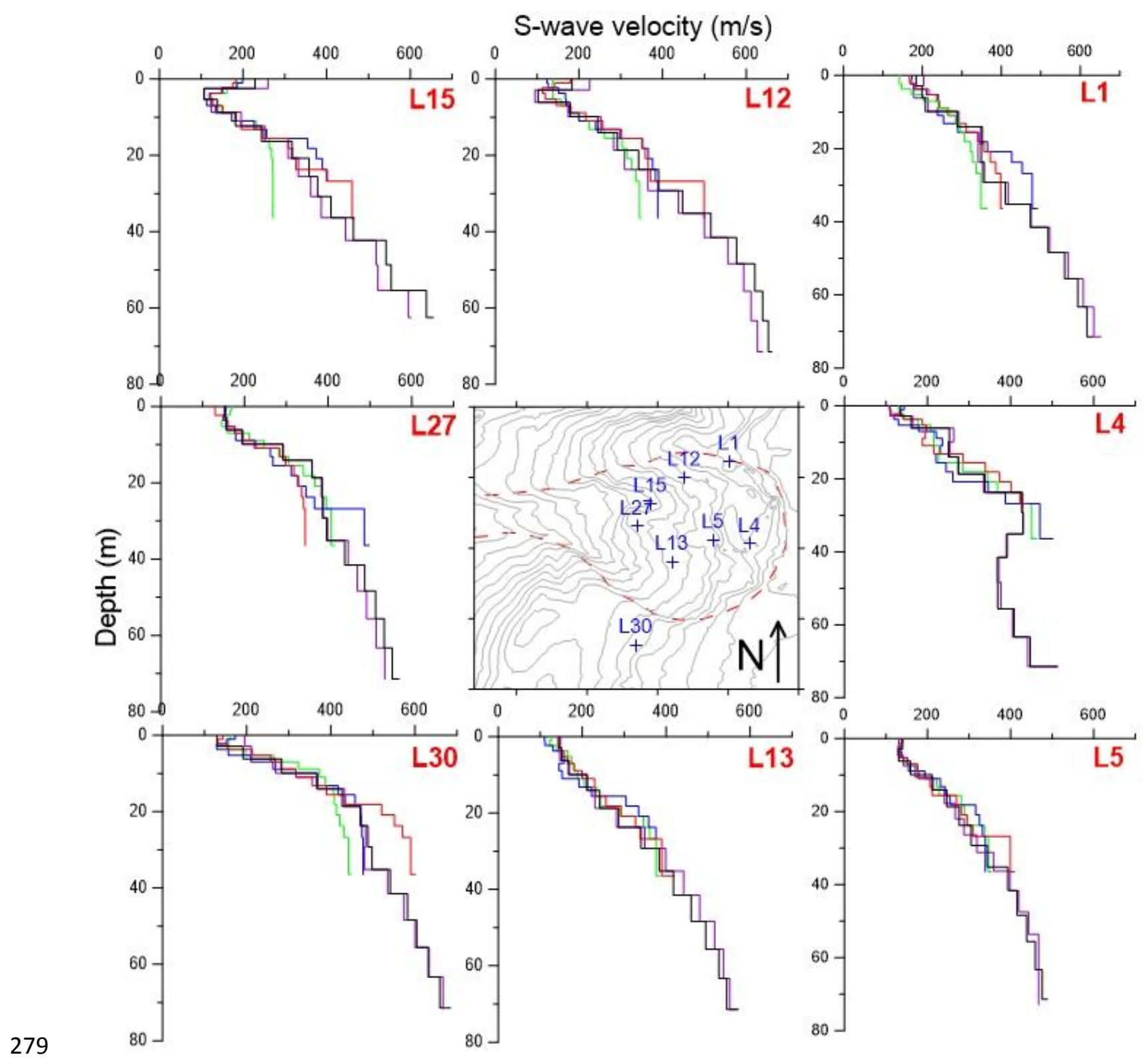

Figure 6. The depth sections of S-wave velocity at sample measurement points. Green, blue and red lines represent the results of MASW measurements for three shots performed at the two ends and in the middle of each profile. The purple lines show the results of the ReMi analysis, and the black lines represent the results of the combine analysis of MASW and 
A general result from the $\mathrm{S}$-wave velocity profiles is that the velocities do not present distinct contrasts, which would be interpreted as failure surface. In general, the velocities gradually increase as depth increases. However, the images of S-wave velocity shown in Figure 7 provide some clues related with the geometry of landslide. The S- wave velocities are very low about $100-200 \mathrm{~m} / \mathrm{s}$ in the top layer, and they increase up to $800 \mathrm{~m} / \mathrm{s}$ at the depth of $80 \mathrm{~m}$. Note that the S-wave velocities are generally lower within the boundary of landslide with respect to the surrounding area. The vertical cross sections of S-wave velocities shown in Figure 8 could be more convenient to interpret the geometry of landslide. The layers with the S-wave velocity lower than $400 \mathrm{~m} / \mathrm{s}$ take place in the middle part of the sections as compatible with the surface boundary of the landslide. The thicknesses of those layers are about 50-60 $\mathrm{m}$ in the middle parts, but change in both transverse and longitudinal direction. The layers with $500 \mathrm{~m} / \mathrm{s}$ or higher velocities extend from the bottom of moving mass to the edges of the landslide area considered as stable parts. In other words, in deeper parts than 60 $\mathrm{m}$, the S-wave velocities begin to be the same for the entire field. So, this depth can be interpreted as the bottom boundary of the landslide mass.

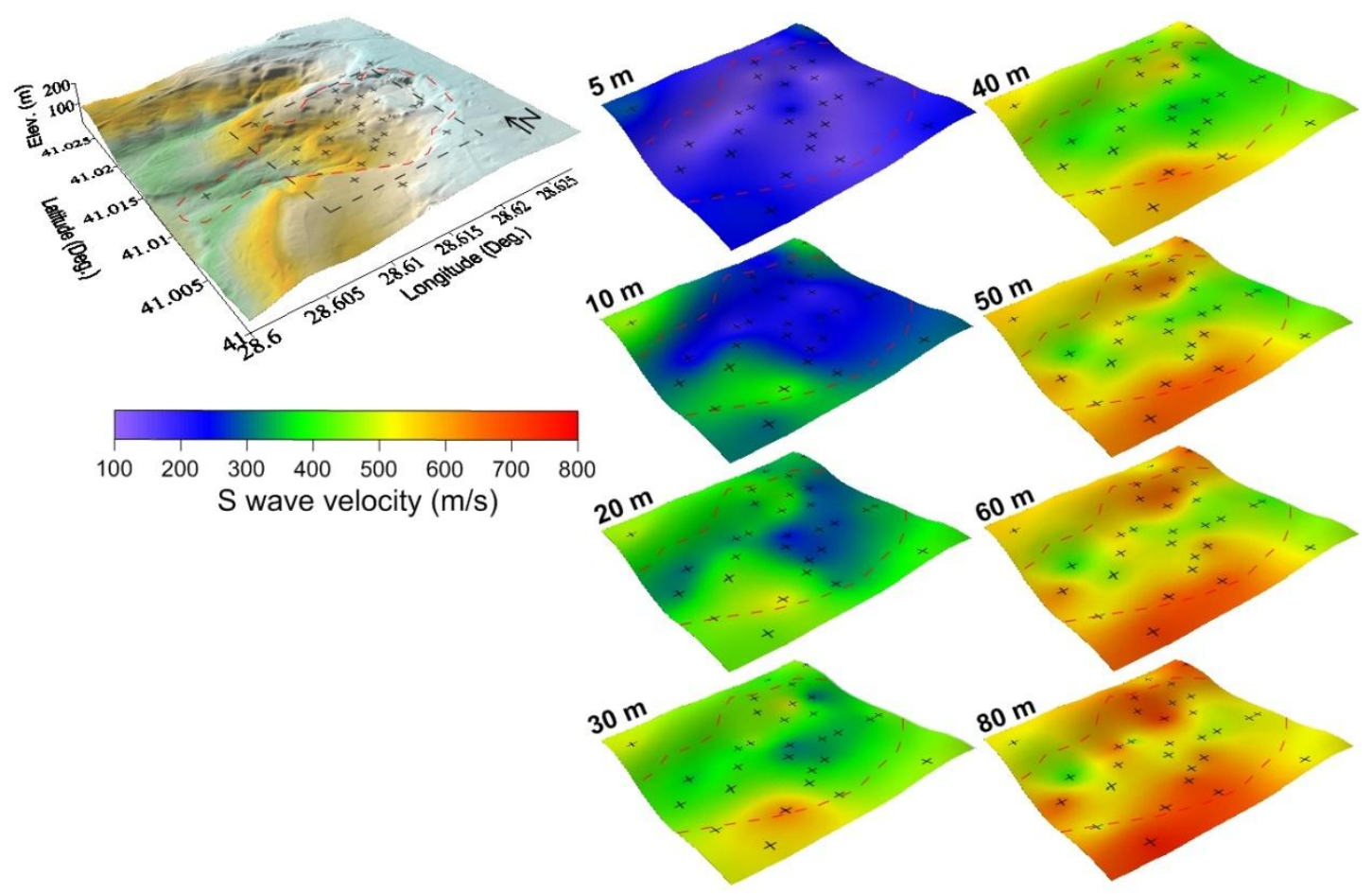


Figure 7. The S-wave velocity images at different depths. Red and black dashed lines show the landslide boundary and the image location on the 3D map, respectively. Cross sign shows the locations of measurement sites.
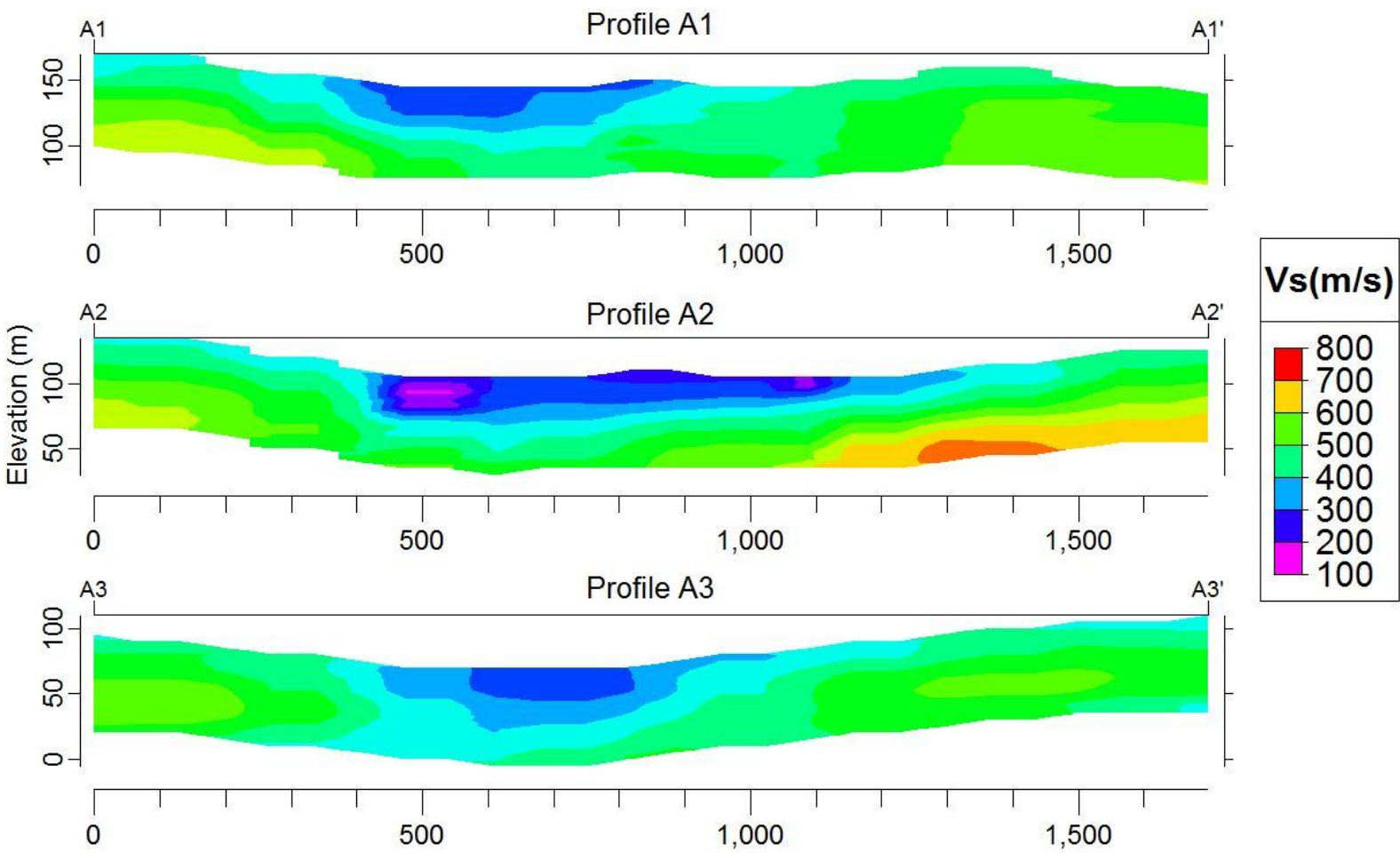

Figure 8. 2D cross sections of $S$-wave velocity. Locations of profiles A1, A2 and A3 match with the locations of sections T1, T2 and T3, respectively, shown in Figure 13.

\subsection{Noise measurements}

Figure 9 shows the distribution of the site resonance frequencies obtained from the $\mathrm{H} / \mathrm{V}$ analysis together with examples of several $\mathrm{H} / \mathrm{V}$ graph. It is to say that to decide resonance frequencies on the H/V curves are very difficult. One of the reasons of this is that the ambient noise records contain some anthropogenic vibrations, which are likely generated by industrial machines working in the region. The fundamental mode frequency of these vibrations is about $1.5 \mathrm{~Hz}$ (e.g. the first peak of M8 site in Figure 9), and they cause a false resonance frequency or they mask a real resonance frequency at some sites. The anthropogenic peaks were identified in three different ways; the sharp peaks on the Fourier spectra, the continuous and equal amplitudes on the time-frequency image, and the azimuth dependence of $\mathrm{H} / \mathrm{V}$ peaks. 
321 Figure 10 shows the identification of anthropogenic peak at $1.5 \mathrm{~Hz}$ at $\mathrm{M} 8$ site. The 322 anthropogenic peaks in the noise measurements are beyond the scope of this paper, but a 323 similar investigation can be found in Yalcinkaya et al. (2013). In the analyses, we tried to 324 keep away from the industrial peaks while determining the resonance peak of the H/V curve. 325 If there is no peak in he $\mathrm{H} / \mathrm{V}$ curve another from the anthropogenic peak, then we kept that 326 site as undetermined. Another reason is that a number of sites in our measurements do not 327 present a clear resonance peak (e.g. M22, M29 sites in Fig. 9) as defined in the SESAME 328 project (Bard and SESAME Team, 2005). At these sites, the resonance frequencies are 329 determined by comparing the H/V curves with those of neighboring sites showing clear peak 330 assuming that the resonance frequency should not change in a few 10 meters, but peculiar 331 conditions for that site, e.g. anthropogenic vibrations or data acquisition, may prevent to see a 332 clear peak. 

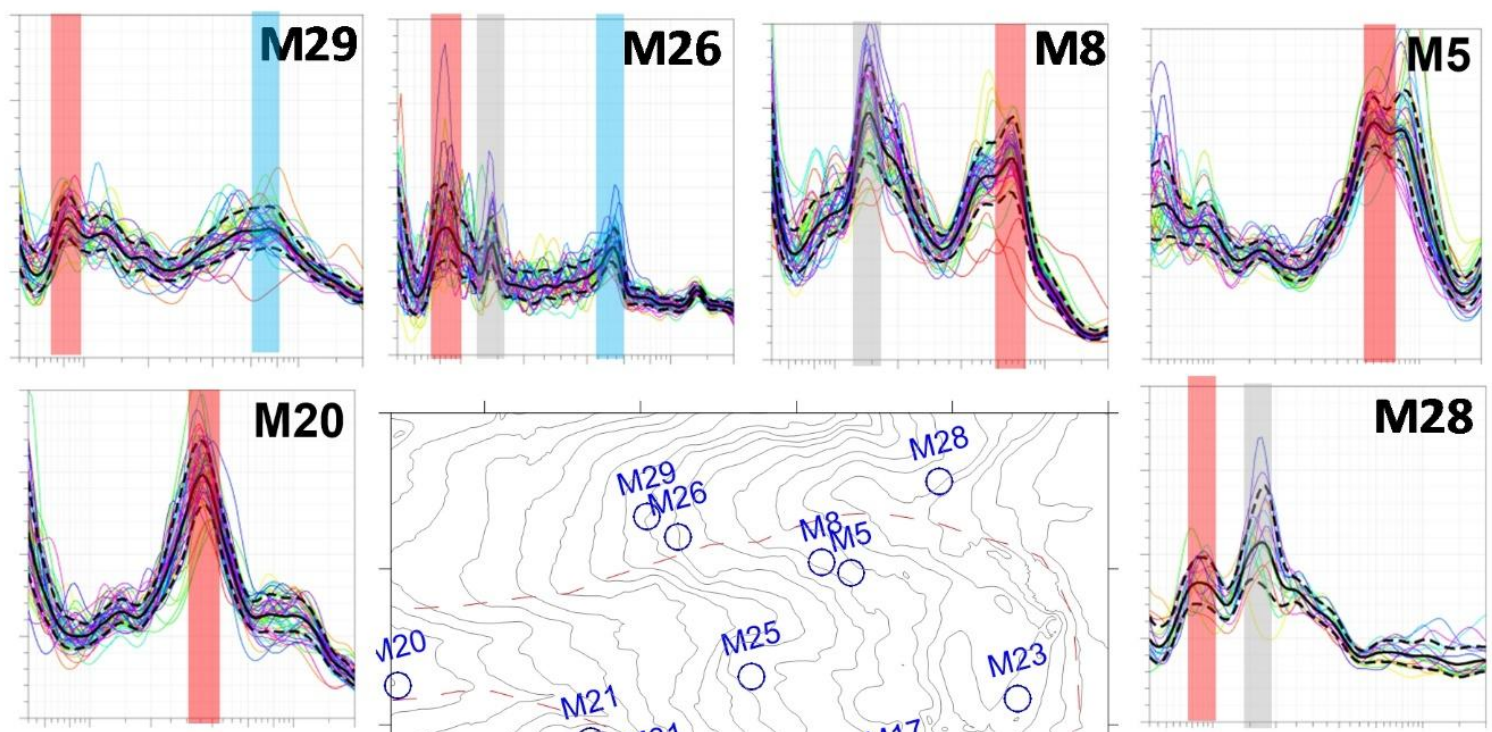
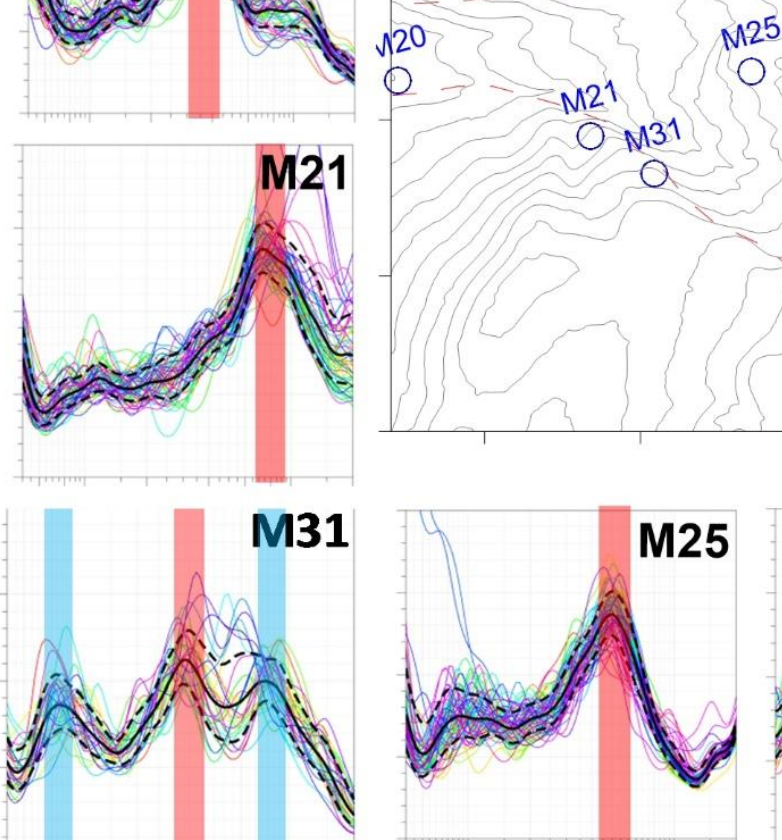

125

0

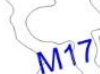

M23

0
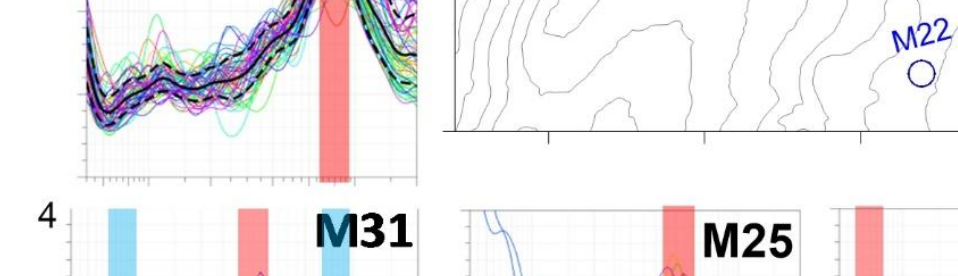

조2

333
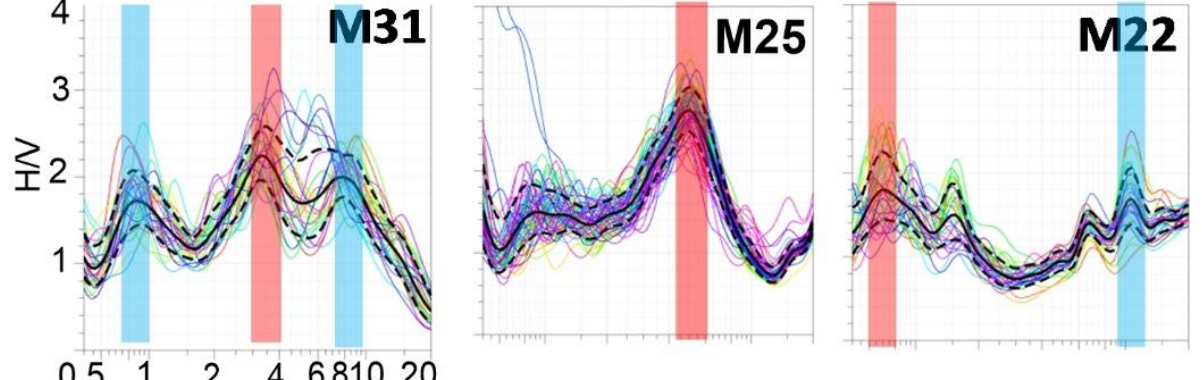
Frequency $(\mathrm{Hz})$
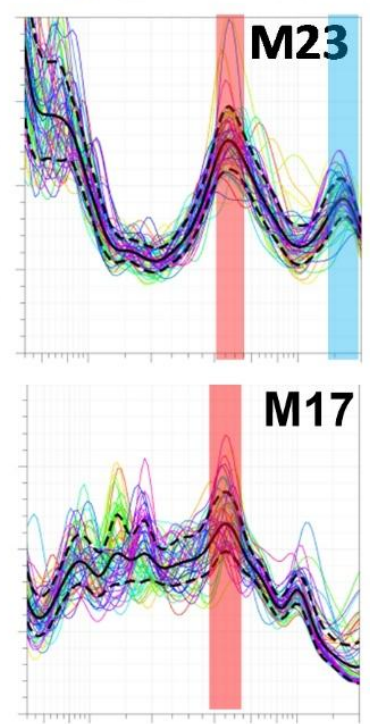


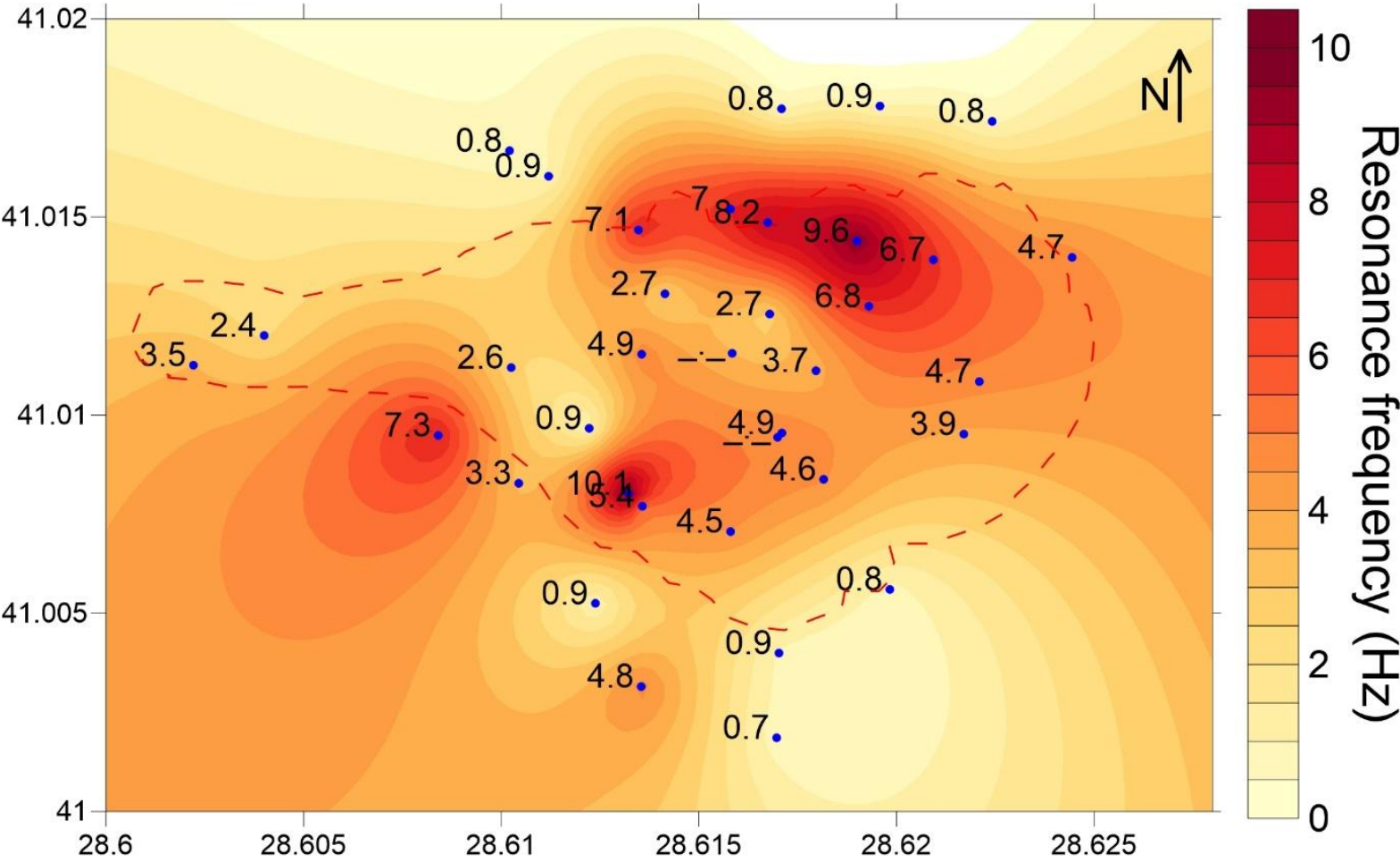

Figure 9. Upper graph represents the examples of $H / V$ curve. Measurement locations are shown on the map in the middle part. The red, blue and grey bars on the H/V curves mark fundamental resonance frequencies, secondary peak frequencies and anthropogenic peaks, respectively. Bottom graph shows the counter map of site resonance frequencies. Numbers show the resonance frequency at each measurement site.
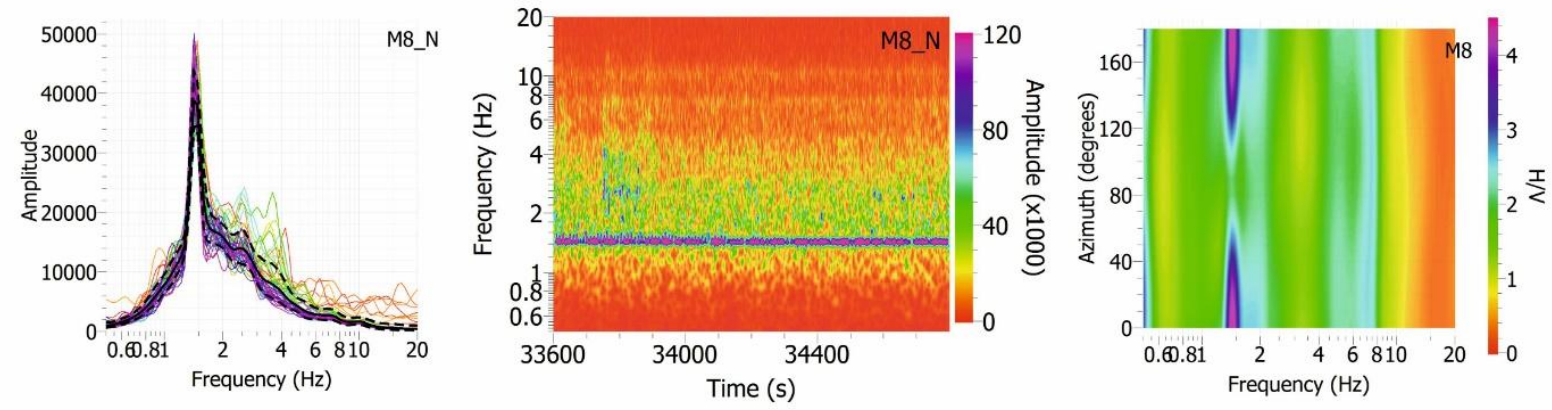

Figure 10. Identification of anthropogenic peak at $1.5 \mathrm{~Hz}$ of site M8. Fourier spectrum of NS component (on the left) exhibits a sharp peak at $1.5 \mathrm{~Hz}$. This peak has continuous and equal amplitudes on the time-frequency spectrum (in the middle). The peak at $1.5 \mathrm{~Hz}$ observed on the rotated $H / V$ ratio (in the right) strongly depends on the azimuth. 
As shown in Figure 9, the resonance frequencies of the sites located within the landslide mass are generally higher than those located outside of landslide. In the middle part of landslide area, the resonance frequencies are observed between $2.7-4.9 \mathrm{~Hz}$, whereas at the sites in the stable area the values decrease to $0.7-0.9 \mathrm{~Hz}$. In addition, high resonance frequencies of 6-10 $\mathrm{Hz}$ are also observed at some transition sites between landslide mass and stable area. The amplitudes of the resonance frequencies especially in the stable area are very small indicating a weak impedance contrast (e.g. M22, M26, M29 sites in Figure 9). Moreover, the H/V curves in the stable area mostly present some secondary peaks at high frequencies, which are likely produced by local slides (e.g. M22, M26, M29, M31 sites in Figure 9). This differentiation of resonance frequencies in the study area is thought that the landslide mass may be generating specific vibration resonance apart from the actual soil resonance. It is encountered similar results in the literature (e.g. Gallipoli et al., 2000; Meric et al., 2007; Jongmans et al., 2009).

The resonance frequencies $\left(f_{r}\right)$ of the $\mathrm{H} / \mathrm{V}$ curves can be converted to soil thicknesses $(H)$ by using empirical relations. Birgoren et al. (2009) suggests a relationship ( $\left.H=150.99 f_{r}^{-1.1531}\right)$ between soil thickness and resonance frequency for the Istanbul region. The soil thicknesses computed from the Birgoren's empirical relation are shown in Figure 11. It is seen that the thickness of the landslide mass ranges from 17 to $50 \mathrm{~m}$, and from 10 to $17 \mathrm{~m}$ on the edges of the landslide. On the stable part, i.e. outside the landslide mass, the soft soil thickness over a seismic bedrock reaches $170-228 \mathrm{~m}$, pointing out a lithological change in deeper deposits. It is also seen a few site, e.g. $170 \mathrm{~m}$ depth in the landslide mass and $25 \mathrm{~m}$ in the stable area, which do not comply with this interpretation.

A borehole was drilled by the TUBITAK (The Scientific and Technological Research Council of Turkey) in the landslide area in the framework of the MARSite project (D62 in Figure 11). Actually, a more comprehensive borehole study on the landslide area has been going on by Istanbul Municipality and TUBITAK, but their results have not been appeared yet. Figure 11 reports the borehole log-stratigraphy, as well. As shown in this log, two failure surfaces have been encountered by the borehole. The depths of the sliding surfaces are about at $30 \mathrm{~m}$ and at $50 \mathrm{~m}$, which are not so different from the depths obtained by the resonance frequencies. 


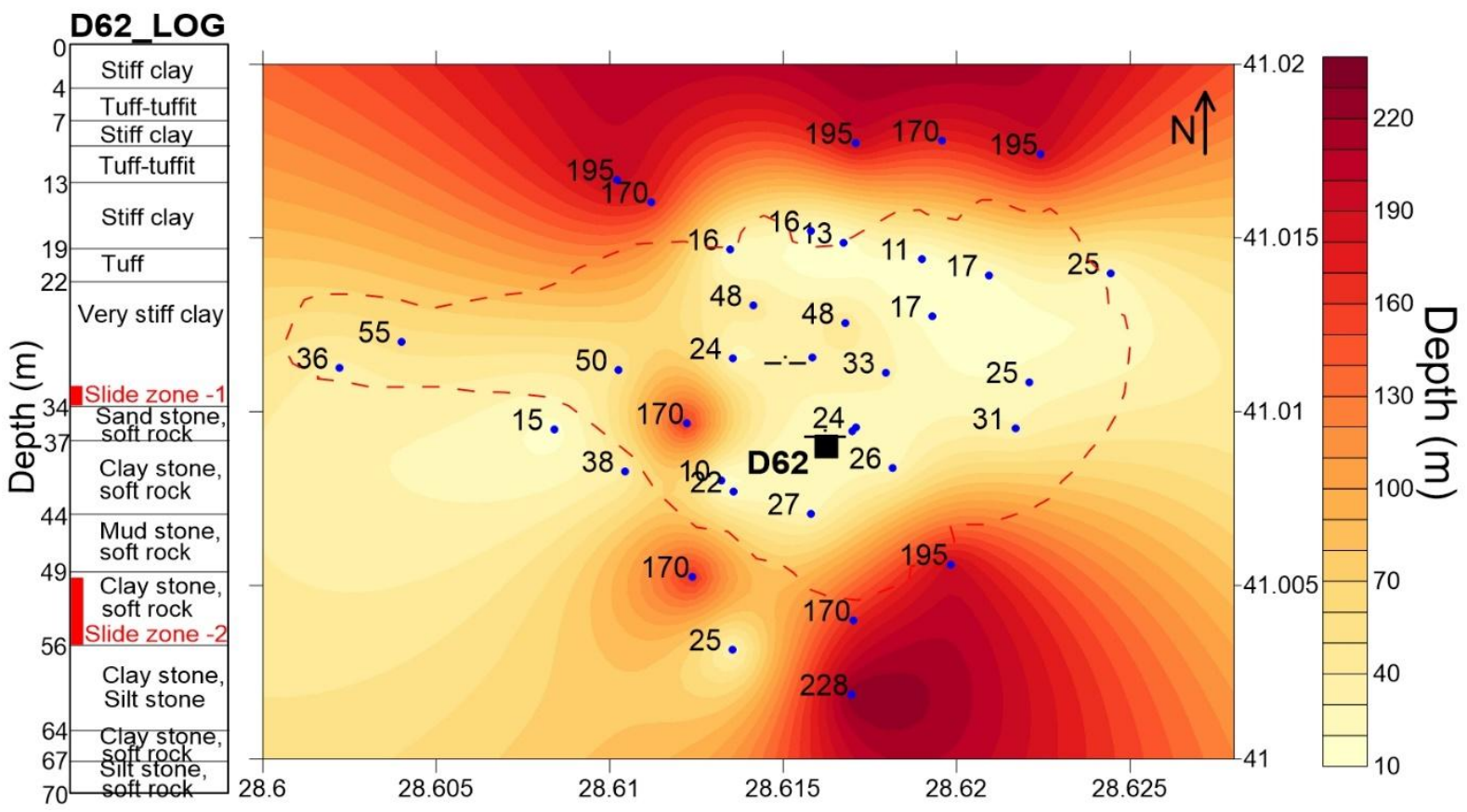

Figure 11. The counter map of soil thicknesses computed from resonance frequencies by the measurement site. It is also shown a lithological section obtained from a borehole shown its location with square on the map.

\subsection{Resistivity measurements}

During the Schlumberger resistivity measurements, the electrode spacing was started from 5 $\mathrm{m}$ for the current electrodes $(\mathrm{AB} / 2)$, and $1 \mathrm{~m}$ for the potential electrodes $(\mathrm{MN} / 2)$. The current was injected to the earth ranging from $50 \mathrm{~mA}$ to $150 \mathrm{~mA}$. The maximum $\mathrm{AB} / 2$ spacing could be applied $120 \mathrm{~m}$ for the VES1 and VES3 profiles, $170 \mathrm{~m}$ for the VES2, and $65 \mathrm{~m}$ for the VES4 (Figure 12). Terrain conditions and instrumental deficiencies did not let larger spacing, so the reliable investigation depths ranged from 30 to $70 \mathrm{~m}(\sim \mathrm{AB} / 4)$. The measurements could not be interpolated to 2D-resistivity sections due to lack of enough measurements, as is done for seismic measurements. Thus, these measurements provided just 1D resistivity depth profiles at a few locations. The analyses of the resistivity measurements are shown in Figure 12. Firstly, noisy resistivity values were manually smoothed, and then the data were interpreted by using the curve matching technique. IPI2WIN software 392 (http://geophys.geol.msu.ru/) was used to invert each sounding curve to a one-dimensional 393 layered model. It was performed RMS-errors lower than 5\% using ground models with 4 to 6 394 layers relied on the bends of resistivity curve. VES1 and VES2 profiles show very low resistivity values lover than $30 \mathrm{ohm}-\mathrm{m}$ along the depth-section, i.e. a typical value for 
remolded clayey debris. These locations take place on the earth flow located on the southern part of the landslide. On the other hand, VES3 and VES4 profiles exhibit a sharp increase of the resistivity up to $120 \mathrm{ohm}-\mathrm{m}$ at almost $20-30 \mathrm{~m}$ below the ground level, that may be related to the secondary failure surfaces. All profiles also show a small rise in resistivity values nearly at $10 \mathrm{~m}$ depths likely corresponding to the gravelly units.
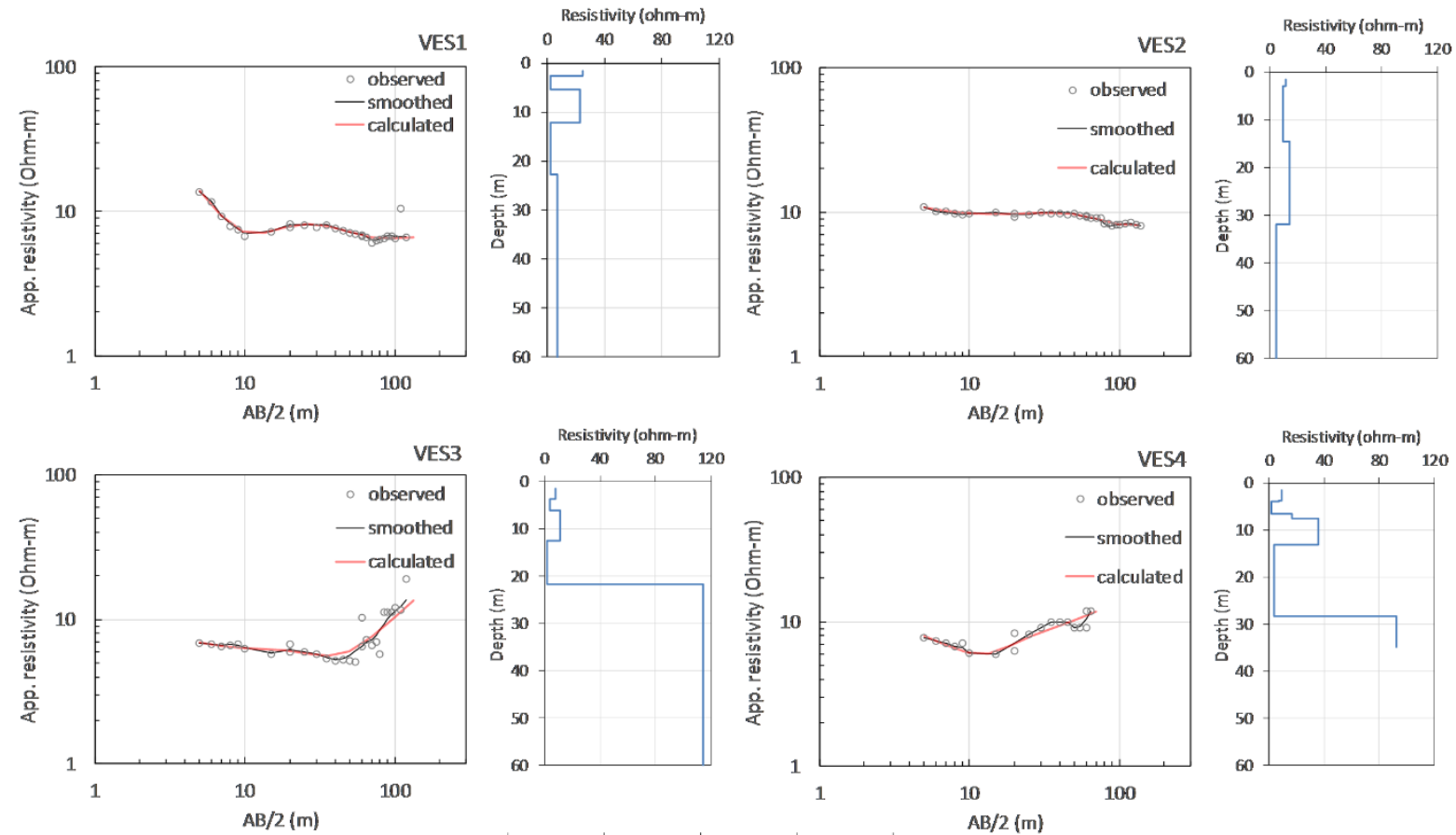

401

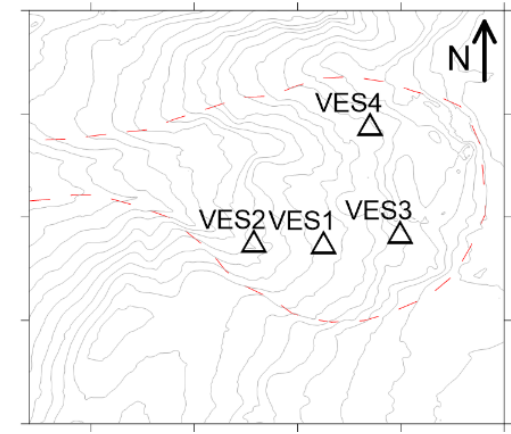

402

Figure 12. $1 D$ ground models obtained from the analysis of resistivity measurements. The observed, smoothed and calculated resistivity values are represented with different symbols on the graphs. The profile locations are shown below on the landslide map.

\section{Discussion and conclusion}

The Buyukcekmece landslide has a very complex structure, so this character complicates the exploring it by geophysical techniques. Bourdeau et al. (2016) constructed a preliminary 
model of Buyukcekmece landslide based on several geomorphological and geological evidences, e.g. the borehole log stratigraphies, the geometries of the scarps, the measured dip of the outcropping strata and a geometrical feedback consisting in a reversal of the present landforms to reconstruct the original shape of the slope (Figure 13). In their models, the landslide mass is divided into 8 blocks indicating repeated reactivations of the landslide and its retrogressive evolution. The results of geophysical measurements have been interpreted taking into account the geological model.
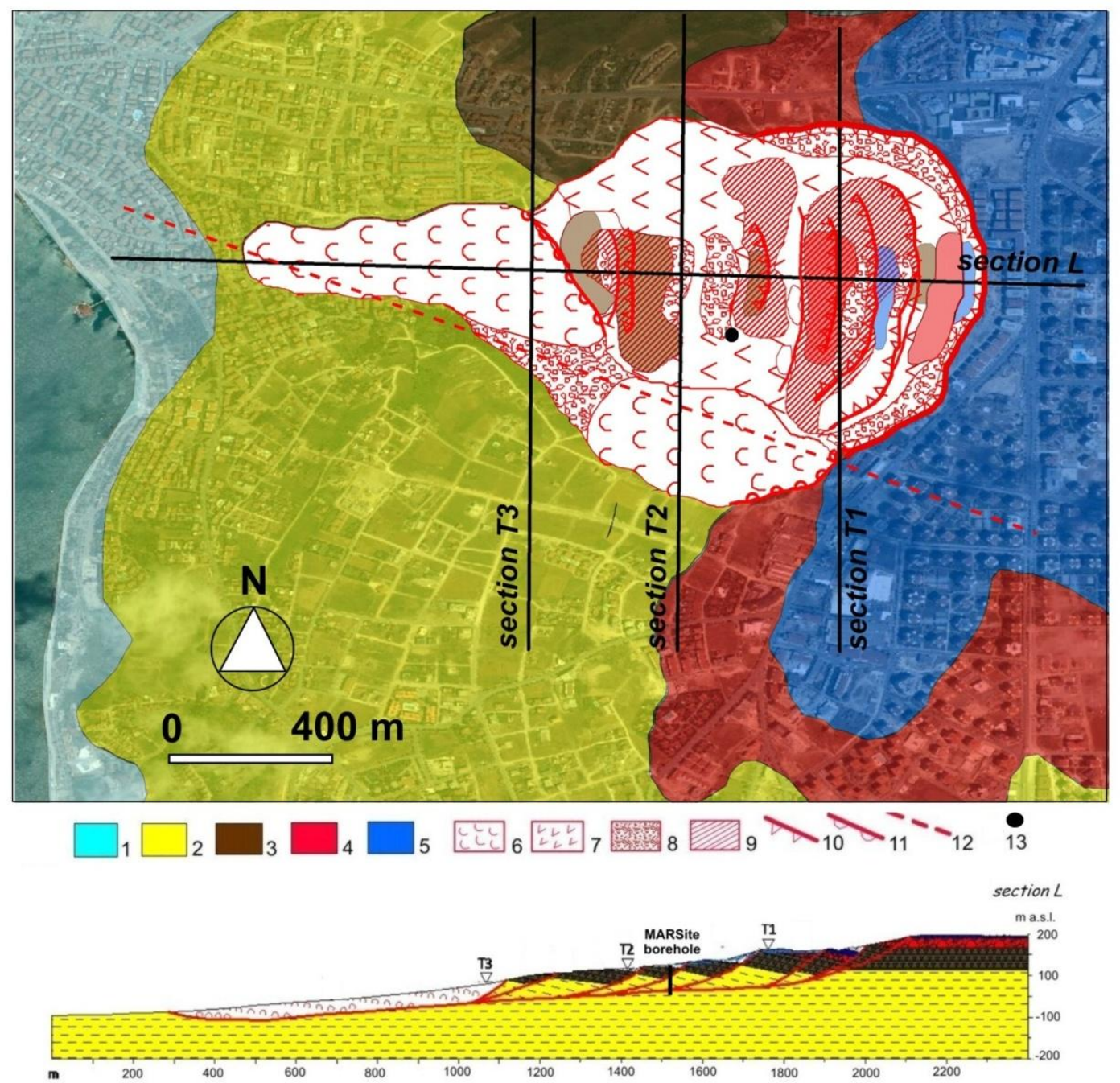

Figure 13. Geological map and geological cross section along trace L of the Buyukcekmece landslide: 1) alluvial and coastal deposits (Holocene); 2) silty-clays of the Gungoren unit of

419 Danismen Formation (upper Oligocene); 3) clays with tuffs of the Cantakoy unit of Danismen 420 Formation (upper Oligocene- lower Miocene); 4) sands and gravels of the Cukurcesme 421 Formation (upper Oligocene- lower Miocene); 5) calcarenites of the Bakirkoy Formation (upper Miocene); 6) earthflow debris; 7) rototranslational landslide mass; 8) slope debris; 
9) landslide counterslope tilted terrace; 10) rototranslational landslide scarp; 11) earthflow crown; 12) fault; 13) D-62 borehole. T1, T2, T3 shows the section lines shown in Figure 8.

The geophysical results reflect an overview of the geological model. The main slip surface of Buyukcekmece landslide develops in the same geological unit consisting of the clayey layers of the Danismen Formation. So, it does not constitute a strong impedance contrast between the landslide mass and underlying layers. It is because of that S-waves do not exhibit important velocity contrasts along the depth-profiles. In addition, the geologic strata of the landslide are not so different than the surrounding area. However, it has been deforming and mixing too much due to ongoing dislocations in terms of surrounding part. The decomposing of materials in the landslide causes lower seismic velocities. The analyses of S-wave velocity clearly reflect this situation. The $S$-wave velocities are lower in the landslide with respect to the stable area. This discrimination continues down to a depth of $60 \mathrm{~m}$, and then the velocities become the same for the entire area. This thickness for the landslide mass is consistent with the geological model. The material consisting of the landslide mass is a mixing of three geological units which are the Bakirkoy, Cukurcesme and the Danismen formations. The average S-wave velocity in this complexity range from $200 \mathrm{~m} / \mathrm{s}$ to $500 \mathrm{~m} / \mathrm{s}$ from the top to the down. However, the velocities vary laterally depending on the block structure of the landslide. It is likely that some of these blocks are more stable than the others and the material consisting of it is more compact. The applied survey plan does not let us investigate each block structure. In a next survey, it should be focused on investigation of the blocks with high resolution measurements.

The complexity of the landslide structure is also evident from the P-wave velocities. The analyses of P-wave velocity did not point out a differentiation between landslide mass and stable area. A reason is that the exploration depth of the refraction analyses remains very shallow. Unfortunately, both using hammer source and strong seismic wave attenuation character of the landslide did not allow to get information from deeper parts than $20 \mathrm{~m}$. In this part, the P-wave velocities range from $300 \mathrm{~m} / \mathrm{s}$ to $2400 \mathrm{~m} / \mathrm{s}$. In general, manmade fills and slope debris on the surface have very low P-wave velocities of about $300 \mathrm{~m} / \mathrm{s}$. Toward the deeper parts, the P-wave velocity increases $1000-2000 \mathrm{~m} / \mathrm{s}$ in the stiff clays of Danismen Formation, and the sands and gravels of Cukurcesme Formation. The sandy deposits of 
Cukurcesme Formation are water-filled (Bourdeau et al. (2016). In locally, the stiff units and the presence of water may have caused to rise P-wave velocities over $1000-1500 \mathrm{~m} / \mathrm{s}$.

The fundamental frequencies of the H/V curves obtained from the microtremor measurements give the thicknesses of soil in the landslide mass between $10-50 \mathrm{~m}$ by using the empirical relation, whereas in the stable area the resonance frequencies are quite low indicating deep lithological changes in the sediments at depths of 170-228 $\mathrm{m}$. The high variability of the fundamental frequencies points out the landslide complexity. Presence of the blocks, fragmentation of the block in itself and secondary slip surfaces may have caused the variation of fundamental frequencies and additionally the secondary frequency peaks at many sites. However, the resolution of the $\mathrm{H} / \mathrm{V}$ analysis is not enough to model all of them. An interesting point is that the $\mathrm{H} / \mathrm{V}$ curves comparatively present clear site resonance peaks on the landslide mass, although S-wave velocities do not show notable contrasts. Moreover, the resonance peaks of $\mathrm{H} / \mathrm{V}$ curves do not present any dependency of azimuth as observed on some landslide cases (e.g. Burjanek et al., 2012; Del Gaudio et al., 2013).

In this study, to produce a reliable result from the resistivity analyses related with the structure of landslide is difficult but the jumping resistivity values at two profiles point out possible slip surfaces at the depths of 20 m's. The resistivity values are quite low as expected due to clayey units and water content. These results coincide with the expected structure of the landslide and the geological observations. It is worth noting that the interpretation of geophysical images needs to correlate with geotechnical investigations. It will be possible when the geotechnical investigations are completed.

Acknowledges: This study is supported by FP7 Marsite project (Grant Agreement No: 308417). We wish to thank all the members of the $6^{\text {th }}$ work package and MARSite project coordinator Prof. N.M. Ozel for their valuable contributions. We wish also thank to workers of TUBITAK-IBB project who gave support our project by providing one of their boreholes for our measurements.

\section{References}


Bard, P.Y., SESAME-Team, 2005. Guidelines for the implementation of the H/V spectral ratio technique on ambient vibrations: measurements, processing, and interpretations. SESAME European research project, EVG1-CT-2000-00026, deliverable D23.12. Available at: http://sesamefp5.obs.ujfgrenoble.fr

Barka, A., Altunel, E., Sunal, G., Cakir, Z., Dikbas, A., Yerli, B. et al., 2002. The surface rupture and slip distribution of the 17 August 1999 Izmit earthquake M 7.4 North Anatolian Fault. Bulletin of Seismological Society America 92, 43-60.

Bird, J.F., Bommer, J.J., 2004. Earthquake losses due to ground failure. Engineering Geology $75,147-179$.

Birgoren, G., Ozel, O., Siyahi, B., 2009. Bedrock depth mapping of the coast south of Istanbul: Comparison of analytical and experimental analyses. Turkish Journal of Earth Science 18, 315-329.

Bourdeau, C., Lenti, L., Martino, S., Oguz, O., Yalcinkaya, E., Bigarrè, P., Coccia, S., 2016. Comprehensive analysis of local seismic response in the complex Buyukcekmece landslide area (Turkey) by engineering-geological and numerical modelling. Engineering Geology (submitted).

Burjanek, J., Moore, J.R., Molina, F.X.Y., Fah, D., 2012. Instrumental evidence of normal mode rock slope vibration. Geophysical Journal International 188, 559-569.

Capizzi, P., Martorana, R., 2014. Integration of constrained electrical and seismic tomographies to study the landslide affecting the cathedral of Agrigento. J. Geophys. Eng. 11, doi:10.1088/1742-2132/11/4/045009.

Caris, J.P.T., Van Asch TH.W.J., 1991. Geophysical, geotechnical and hydrological investigations of a small landslide in the French Alps. Eng. Geol., 31, 249-276.

Chianese, D., Lapenna, V., Di Salvia, S., Perrone, A., Rizzo, E., 2010. Joint geophysical measurements to investigate the Rossano of Vaglio archaeological site (Basilicata Region, Southern Italy). Journal of Archaeological Science 37, 2237-2244.

Cruden, D.M., Varnes, D.J., 1996. Landslide types and processes, in Landslides: Investigation and Mitigation. A.K. Turner and R.L. Schuster (Editors), Transportation Research Board, 
Spec. Report 247, National Research Council, National Academy Press, Washington, DC:3675.

Dalgic, S., 2004. Factors affecting the greater damage in the Avc1lar area of Istanbul during the 17 August 1999 Izmit earthquake. Bull Eng Geol Env 63, 221-232.

Del Gaudio, V., Wasowski, J., Muscillo, J., 2013. New developments in ambient noise analysis to characterise the seismic response of landslide-prone slopes. Nat. Hazards Earth Syst. Sci.13, 2075-2087.

Duman, T.Y. et al., 2004. Istanbul Metropolu Batısındaki (Küçükçekmece-Silivri-Çatalca Yöresi) Kentsel Gelişme Alanlarının Yerbilim Verileri. Maden Tetkik ve Arama Genel Müdürlüğü (MTA) Özel Yayın Serisi - 3, Ankara.

Duman, T.Y., Can, T., Gokceoglu, C., Nefeslioglu, H.A., Sonmez, H., 2006. Application of logistic regression for landslide susceptibility zoning of Cekmece Area, Istanbul, Turkey. Environ Geol 51, 241-256.

Ergintav, S., Demirbag, E., Ediger, V., Saatcilar, R., Inan, S., Cankurtaranlar, A., Dikbas, A., Bas, M., 2011. Structural framework of onshore and offshore Avcilar, Istanbul under the influence of the North Anatolian fault. Geophys J Int 185, 93-105.

Gallipoli, M., Lapenna, V., Lorenzo, P., Mucciarelli, M., Perrone, A., Piscitelli, S., Sdao, F., 2000. Comparison of geological and geophysical prospecting techniques in the study of a landslide in southern Italy. European J. Env. Eng. Geophys., 4, 117-128.

Hack, R., 2000. Geophysics for slope stability. Surveys in Geophysics 21, 423-448.

Hubert-Ferrari, A., Barka, A., Jacques, E., Nalbant, S.S., Meyer, B., Armijo, R. et al., 2000. Seismic hazard following the 17 August 1999 Izmit earthquake. Nature 404, 269-273.

Jongmans, D., Garambois, S., 2007. Geophysical investigation of landslides: a review. Bulletin Societe Geologique de France 178 (2), 101-112.

Jongmans, D., Bievre, G., Renalier, F., Schwartz, S., Beaurez, N., Orengo, Y., 2009. Geophysical investigations of a large landslide in glaciolacustrine clays in the Trieves area (French Alps). Engineering Geology 109 (1-2), 45-56. 
Keay, S., Earl, G., Hay, S., Kay, S., Ogden, J., Strutt, K.D., 2009. The role of integrated geophysical survey methods in the assessment of archaeological landscapes: the case of Portus. Archaeol. Prospect. 16, 154-166.

King, G.C.P., Hubert-Ferrari, A., Nalbant, S.S., Meyer, B., Armijo, R., Bowman, D., 2001. Coulomb interactions and the 17 August 1999 Izmit, Turkey earthquake. Earth Planet Sci 333, $557-569$.

Lapenna, V., Lorenzo, P., Perrone, A., Piscitelli, S., Rizzo, E., Sdao, F., 2005. 2D electrical resistivity imaging of some complex landslides in Lucanian Apennine chain, southern Italy. Geophysics, 70, B11-B18.

Martino, S., Bigarrè, P., Coccia, S., Bourdeau, C., Lenti, L., Oguz, O., Yalcinkaya, E., 2016. Integrated engineering-geological and numerical approach applied to the large Buyukcekmece (Turkey) landslide for evaluating earthquake-induced effects. Landslides and Engineered Slopes. Experience, Theory and Practice - Aversa et al. (Eds), 1375-1382.

McCann, D.M., Forster, A., 1990. Reconnaissance geophysical methods in landslide investigations. Eng. Geol., 29, 59-78.

Meric, O., Garambois, S., Malet, J.-P., Cadet, H., Gueguen, P., Jongsman, D., 2007. Seismic noise-based methods for soft-rock landslide characterization. Bull Soc Geol Fr 178(2), 137148.

Nakamura, Y., 1989. A method for dynamic characteristics estimation of subsurface using microtremor on the ground surface. QR Rail Tech Res Inst 30, 25-30.

Ozgul, N. et al., 2005. İstanbul il alanının genel jeoloji ozellikleri, İBB Deprem ve Zemin İnceleme Müd., 79 pp., İstanbul.

Panzera, F., Lombardo, G., 2013. Seismic property characterization of lithotypes cropping out in the Siracusa urban area, Italy. Engineering Geology 153, 12-24.

Pondard, N., Armijo, R., King, G.C.P., Meyer, B., Flerit, F., 2007. Fault interactions in the Sea of Marmara pull apart (North Anatolian Fault): earthquake clustering and propagating earthquake sequences. Geophys J Int, doi: 10.1111/j.1365-246X.2007.03580.x

Parsons, T., Toda, S., Stein, R.S., Barka, A., Dieterich, J.H., 2000. Heightened odds of large earthquakes near Istanbul: an interaction-based probability calculation. Science 288, 661-665. 
567 Parsons, T., 2004. Recalculated probability of M C 7 earthquakes beneath the Sea of Marmara

568 Turkey. J Geophys Res 109, B05304. doi:10.1029/2003JB002667

569 Petley, D., 2010. Global patterns of loss of life from landslides. Geology 40(10), 927-930.

570 Sen, S., 2007. A fault zone cause of large amplification and damage in Avcilar (W Istanbul)

571 during 1999 Izmit earth-quake. Nat Hazards 43, 351-363.

572 Schmutz, M., Albouy, Y., Guerin, R., Maquaire, O., Vassal, J., Schott, J.-J., Descloitres, M., 573 2000. Joint electrical and time domain electromagnetism (TDEM) data inversion applied to 574 the Super Sauze earthflow (France). Surveys in Geophys., 21, 371-390.

575 Utkucu, M., Kanbur, Z., Alptekin, O., Sunbul, F., 2010, Seismic behavior of the North 576 Anatolian Fault beneath the Sea of Marmara (NW Turkey): implications for earthquake 577 recurrence times and future seismic hazard. Nat Hazards 50, 45-71.

578 Yalcinkaya, E., Tekebas, S., Pinar, A., 2013. Analysis of ambient noise in Yalova, Turkey: 579 discrimination between artificial and natural excitations. J Seismol 17, 1021-1039. 